\title{
Topographic Effects on the Luzon Diurnal Cycle during the BSISO $\mathscr{}$
}

\author{
Emily M. Riley Dellaripa, ERic D. Maloney, Benjamin A. Toms, Stephen M. Saleeby, \\ AND SUSAN C. VAN DEN HEEVER \\ Department of Atmospheric Science, Colorado State University, Fort Collins, Colorado
}

(Manuscript received 21 February 2019, in final form 10 September 2019)

\begin{abstract}
Cloud-resolving simulations are used to evaluate the importance of topography to the diurnal cycle (DC) of precipitation (DCP) over Luzon, Philippines, and surrounding ocean during the July-August 2016 boreal summer intraseasonal oscillation (BSISO) event. Composites of surface precipitation for each 30-min time increment during the day are made to determine the mean DCP. The mean DCP is computed separately for suppressed and active BSISO conditions and compared across three simulations with varying topographyflat, true, and doubled topographic height. The magnitude of the topographic height helps to dictate the timing, intensity, and location of diurnal precipitation over and near Luzon. For example, the mean DCP in the true topography run peaks $1.5 \mathrm{~h}$ later, is broader by $1 \mathrm{~h}$, and has a $9 \%$ larger amplitude during active conditions relative to suppressed conditions. By contrast, the flat run mean DCP is earlier and narrower by $0.5 \mathrm{~h}$ with a $5 \%$ smaller amplitude during active conditions versus suppressed conditions. Within the suppressed or active BSISO conditions, the mean DCP peak and amplitude increase as the topographic height increases. The presence of elevated topography focuses precipitation over the coastal mountains during suppressed conditions, while dictating which side of the domain (i.e., east Luzon and the Philippine Sea vs west Luzon and the South China Sea) more precipitation occurs in during active conditions. These topographic-induced changes are discussed in terms of mechanical and thermodynamic forcing differences between the two large-scale BSISO regimes for the three runs.
\end{abstract}

\section{Introduction}

Tropical intraseasonal oscillations (ISOs) are 30-90-day modes of tropical convection that generally initiate in the Indian Ocean (Zhang 2005; Lee et al. 2013). During the boreal winter, the Madden-Julian oscillation (MJO) is the dominant tropical ISO with convection propagating predominantly eastward over the Maritime Continent (MC) and waning in the central Pacific (Madden and Julian 1972; Zhang 2005). The MC includes the water and islands in the area of $10^{\circ} \mathrm{S}-20^{\circ} \mathrm{N}, 90^{\circ}-150^{\circ} \mathrm{E}$ (Neale and Slingo 2003). Boreal summer ISO (BSISO) convection, however, propagates both northward and eastward, passing over the Philippines before waning in the northwest Pacific (Kikuchi et al. 2012; Lee et al. 2013).

Supplemental information related to this paper is available at the Journals Online website: https://doi.org/10.1175/JAS-D-190046.s1.

Corresponding author: Emily M. Riley Dellaripa, emily.riley@ colostate.edu
Despite decades of research, a complete understanding of the ISOs is still lacking. Most general circulation models (GCMs) fail to adequately reproduce the MJO and BSISO (e.g., Jiang et al. 2015; Neena et al. 2017). One struggle that GCMs have is the handling of ISO amplitude and propagation over the MC (e.g., Fig. 4 in Jiang et al. 2015). For example, observations show a local minimum in cloud cover over the $\mathrm{MC}$ as the $\mathrm{MJO}$ propagates eastward (e.g., Knutson and Weickmann 1987; Maloney and Hartmann 1998; Hsu and Lee 2005; Riley et al. 2011) indicating a weakening of the MJO over the MC before reintensifying in the western Pacific. This MJO weakening or disruption of its propagation may result from the interaction of convection with high MC topography (e.g., Hsu and Lee 2005; Inness and Slingo 2006; Wu and Hsu 2009; Tseng et al. 2017; Tan et al. 2018). Tan et al. (2018) simulations of the April 2009 MJO event suggest that the impact of topography on simulated MJOs is somewhat dependent on model resolution and parameterized versus explicitly resolved convection. High-resolution simulations (4-km grid spacing) with explicitly resolved convection captured the eastward propagation of the MJO over the MC 
regardless of the presence versus absence of topography. Low-resolution simulations (12-km grid spacing) with parameterized convection only captured the eastward propagation of the MJO over the MC in the absence of topography. Other papers have shown that explicitly resolving topography with higher-resolution models leads to improved MJO characteristics (e.g., Rajendran et al. 2008; Liu et al. 2009). Though a similar weakening of BSISO convection or disruption to BSISO propagation through land and topography interaction has not explicitly been discussed in the literature, Figs. 4 and 10 of Neena et al. (2017) and Fig. 3 of Sobel et al. (2010) imply such interactions are possible and serve as motivation for this work to explicitly understand the impact topography has on the diurnal cycle of precipitation during BSISO suppressed versus active conditions.

Along with the effects of topography over the MC on MJO evolution, previous work has suggested that the diurnal cycle (DC) of precipitation (DCP) over the MC has important interactions with the MJO. Oh et al. (2013) showed enhanced intraseasonal variance over the $\mathrm{MC}$ and a smoother propagation of the MJO across the $\mathrm{MC}$ in their GCM model simulation of four boreal winter seasons when their model was nudged to daily, as opposed to diurnally, varying Tropical Rainfall Measuring Mission (TRMM) rainfall and prognostic National Centers for Environmental Prediction (NCEP) Reanalysis 2 (R2) variables. Similarly, Hagos et al. (2016) found enhanced MJO convection and successful propagation of the MJO through the $\mathrm{MC}$ region when fixed versus diurnally varying solar radiation was used in their cloud-permitting regional simulations of the November 2011 MJO event. Both studies reason that the absence of the DCP frees up moisture to enhance $\mathrm{MJO}$ convection and its ability to traverse the MC thereby suggesting that the DC is key to understanding the different behavior of MJO maintenance and propagation over the MC, impacts that are also likely to manifest during boreal summer ISOs.

Other studies have focused on the changes in amplitude and phase of the DCP over the MC through different MJO large-scale conditions. Using TRMM observations, Peatman et al. (2014) found that the DCP amplitude over MC land peaks just prior to the arrival of large-scale active MJO convection. Birch et al. (2016) reached a similar conclusion with TRMM observations and regional climate model simulations, but focused on the DCP over Sumatra during different large-scale MJO conditions. Cloud-resolving model (CRM) simulations of an MJO event over New Guinea by Vincent and Lane (2016) also showed increased DCP amplitude over New Guinea land prior to the arrival of MJO active conditions. However, TRMM 3B42 and Climate Prediction Center morphing technique (CMORPH) observations examined by Vincent and Lane (2016) over New Guinea contradicted their modeling results by showing a similar DCP amplitude just prior to and during the most active MJO conditions over the MC. Several papers based on observations have found that the amplitude of the DCP over MC land peaked during MJO suppressed conditions (Sui and Lau 1992; Ichikawa and Yasunari 2006; Rauniyar and Walsh 2011; Wang et al. 2011; Yokoi et al. 2017), while other papers found the opposite result with peak DCP amplitude over MC land during MJO active conditions (Chen and Houze 1997; Sui et al. 1997a,b; Tian et al. 2006). These works also showed conflicting results in DCP phase changes during active versus suppressed MJO conditions over the MC. Sui et al. (1997a,b), Tian et al. (2006), and Wang et al. (2011) found the DCP phase over MC land to be the same regardless of largescale MJO conditions, whereas Chen and Houze (1997) and Rauniyar and Walsh (2011) found the DCP phase to differ between suppressed and active MJO conditions. Rauniyar and Walsh (2011) noted that the DCP peak during active conditions lags the suppressed conditions peak by about $1-2 \mathrm{~h}$. These conflicting results indicate that amplitude and phase changes of the DCP with MJO large-scale condition over the $\mathrm{MC}$ are dependent on specific locations within the MC, the method of analysis employed, and the number of events studied, all of which varied from study to study. All the studies described in this paragraph focused on the MJO during the boreal winter, except for Ichikawa and Yasunari (2006), whose analysis encompassed both boreal summer and winter. Since our study focuses on the DCP during the boreal summertime ISO (i.e., the BSISO), the above discussion of previous papers focused on the MJO may not be directly relevant to our work. The above papers are reviewed to highlight the complexity of the DCP throughout the MC.

There are fewer studies focused on the interaction of ISOs with the MC DCP for BSISOs than for the MJO [i.e., Chen and Takahashi (1995), Ho et al. (2008), and Park et al. (2011) vs the papers discussed above]. During May-September, the DCP amplitude over land in the South China Sea (SCS) is enhanced during suppressed BSISO conditions due to a stronger sea breeze arising from enhanced land-sea thermal contrasts from reduced overall cloudiness compared to active BSISO conditions (Chen and Takahashi 1995). However, there is little difference in the DCP phase in and around the SCS between BSISO active versus suppressed conditions (Chen and Takahashi 1995). During active BSISO conditions, TRMM rainfall observations over the Philippines in June and August peak in the late afternoon and midmorning (Ho et al. 2008; Park et al. 2011). For inactive BSISO conditions, rainfall initiates over land in the late 
afternoon and then strengthens overnight as it moves off the west coast of the Philippines with maximum rainfall occurring offshore near midnight local time (LT; Ho et al. 2008). MM5 sensitivity experiments of the June 2004 BSISO event used fixed and diurnally varying solar radiation to determine that diurnal variations in radiation are key to inducing afternoon convergence over land and morning convergence off the west coast of the Philippines (Park et al. 2011). The differences in the MM5 experiments were attributed to a lack of sea- and land-breeze circulations in the fixed-radiation simulation. We note that it is difficult to pinpoint consistent similarities and differences between the DCP of the MJO versus BSISO because results vary among studies and the behavior of the DCP during the MJO seems to depend on location within the MC.

Topography can have important impacts on the DCP, rendering examination of the effects of topography on the DCP within ISO events useful. Daytime elevated heating along topography can induce upslope mountainvalley breezes (e.g., Houze 2012; Kirshbaum et al. 2018) that may work in concert with land-sea breezes to enhance DC circulations along mountainous coastal regions (e.g., Qian 2008). When Qian (2008) flattened the topography in their regional-climate model simulations of 30 years of December-February convection over Java, the strength of the Java land-sea breeze was slightly weaker, with precipitation distributed more over the coastlands and an earlier peak in the DCP over land than the control run that had topography. Like Qian (2008), Barthlott and Kirshbaum (2013) and Zhu et al. (2017) examined the role of topography on the DCP over islands through terrainaltering CRM experiments. Barthlott and Kirshbaum (2013) found that topography was important to the DCP over two Mediterranean islands during a 26 August 2009 case study. As topography increased, convection initiated earlier and shifted to the lee side of the mountains on the two islands. However, Zhu et al. (2017) found that topography was not important to the timing or intensity of the DCP over Hainan Island in their monthlong CRM simulations that were initialized and nudged at the boundaries using the average May and June of 2006-15 ERA-Interim data (Dee et al. 2011). Therefore, topographic effects on the DCP may be location specific. Though Qian (2008), Barthlott and Kirshbaum (2013), and Zhu et al. (2017) did not examine how these DC changes due to topography interacted with ISO regimes, such changes could vary depending on ISO regime. For example, Ichikawa and Yasunari (2006) discuss how interactions of Borneo's DCP and different MJO regimes with Borneo's topography alter the timing, strength, type (i.e., convective vs stratiform) and propagation characteristics of precipitation across Borneo.
Given that topography can have important impacts on the DCP and the DCP has been shown to affect MJO maintenance and propagation (discussion above), our goal is to pinpoint the effects of topography on the DCP through different large-scale ISO conditions. This paper focuses on the role of topography on the DCP over and surrounding Luzon, Philippines, during the July-August 2016 BSISO event. A BSISO event over Luzon, Philippines, was chosen for several reasons: 1) Luzon intercepts BSISO northeastward propagation and will therefore capture both active and suppressed ISO large-scale conditions, 2) Luzon allows us to examine both land and ocean DCP changes throughout a BSISO event, 3) prior work has concentrated more on interactions of the boreal wintertime MJO with islands in the southern MC (i.e., south of the Philippines) compared to BSISO interactions with the MC (i.e., papers discussed above), and 4) this work aligns with a recent field program called Propagation of Intraseasonal Tropical Oscillations (PISTON) that is funded by an Office of Naval Research Departmental Research Initiative to better understand ISO maintenance and propagation.

The July-August 2016 BSISO event was simulated with a CRM in a set of sensitivity experiments in which topography was altered over Luzon to address the following two questions: 1) How does topography affect the DCP over Luzon and surrounding seas, and 2) how does that effect differ across large-scale BSISO active versus suppressed conditions?

The following section describes the CRM and observations used in this work. Section 3 discusses the fidelity of the model compared to observations, while section 4 examines the DCP over Luzon during different BSISO conditions for the set of sensitivity runs. Section 5 offers explanations for the results, and section 6 summarizes the study and provides conclusions.

\section{Model and data description and methods}

\section{a. Model description}

CRM simulations were completed with the Regional Atmospheric Modeling System, version 6.2 (RAMS; Pielke et al. 1992; Cotton et al. 2003; Saleeby and van den Heever 2013). RAMS is a fully compressible, nonhydrostatic CRM that uses two-moment bulk microphysics, the Harrington radiation scheme (Harrington 1997), and the Land Ecosystem-Atmosphere Feedback, version 3 (LEAF3; Walko et al. 2000; Walko and Tremback 2005) land surface submodel to represent surfaceatmosphere moisture and heat exchange. The radiation scheme is fully interactive with the microphysics and LEAF3. Mixing ratio and number concentration are predicted by the microphysics scheme for seven hydrometeor 
classes: cloud droplets, rain, pristine ice, snow, aggregates, graupel, and hail (Walko et al. 1995; Meyers et al. 1997; Saleeby and Cotton 2004; Saleeby and van den Heever 2013). Ice nucleation is represented with the DeMott et al. (2010) scheme. Maximum ice nuclei concentration is set at $0.01 \mathrm{mg}^{-1}\left(0.0125 \mathrm{~cm}^{-3}\right.$ at the surface) and a static cloud condensation nuclei profile is used with maximum concentration set at $100 \mathrm{mg}^{-1}$ $\left(125 \mathrm{~cm}^{-3}\right)$. These concentrations were used successfully in a radiative convective equilibrium simulation with RAMS (Igel et al. 2017).

For all simulations the model domain is $1000 \mathrm{~km} \times$ $1000 \mathrm{~km}$ in extent, has horizontal grid spacing of $2 \mathrm{~km}$, and is centered over Luzon (Fig. 1). There are 42 stretched vertical levels up to $25 \mathrm{~km}$. The lowest levels are $125 \mathrm{~m}$ apart with seven model levels occurring under $1 \mathrm{~km}$, while the top 13 levels are spaced $1 \mathrm{~km}$ apart. A vertical stretch ratio of 1.08 is utilized. RAMS uses a sigma terrain-following coordinate system. The time step is $5 \mathrm{~s}$ with output saved every $30 \mathrm{~min}$.

Three simulations were completed to address the effect of topography on the Luzon DCP through different BSISO regimes. The simulations were identical except for the height of topography in each run. The control simulation used true topography and is referred to as the true topography run. One sensitivity simulation set all of the Luzon terrain height to zero, thus maintaining the land-ocean distinction, but with flat land. This simulation is referred to as the flat run. Another sensitivity simulation doubled the Luzon terrain height and is referred to the doubled topography run. The true and doubled topography runs are sometimes referred to collectively as the elevated topography runs. Previous studies have used a similar approach of altering terrain height to study the effects of topography on precipitation (e.g., Barthlott and Kirshbaum 2013; Rasmussen and Houze 2016; Zhu et al. 2017). All simulations used observed weekly averaged NOAA optimum interpolation sea surface temperatures (OI SSTs; Reynolds et al. 2002).

Each simulation is initiated with horizontal winds, temperature, pressure (Exner function), water vapor mixing ratio, and soil moisture and temperature from the fifth generation of the European Centre for MediumRange Weather Forecasts (ECMWF) reanalysis (ERA5; Copernicus Climate Change Service 2017). ERA5 has 31-km horizontal resolution at a 1-hourly time scale. RAMS interpolates ERA5 to the simulation horizontal and vertical grid spacing. Lateral and top boundary nudging of the variables listed above, except for soil moisture and temperature, is applied using ERA5 with a 15-min time scale for the outermost 50 grid points for the lateral boundary nudging and the top $5 \mathrm{~km}$ of the model for the top boundary nudging. RAMS's lateral boundary-nudging

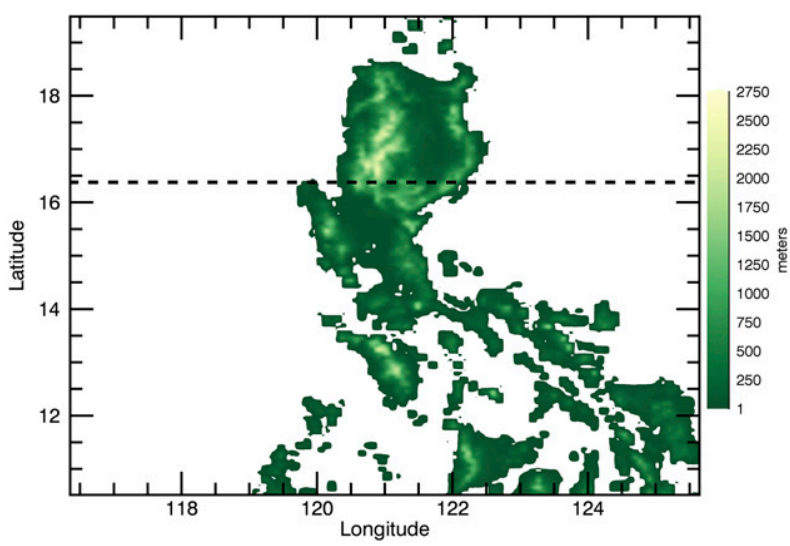

FIG. 1. Model domain with true topography. The area north of the dashed line is defined as northern Luzon and used in some figures below.

scheme follows Davies (1976) in which the user defined nudging time scale (i.e., $15 \mathrm{~min}$ in our case) increases parabolically to infinity from the boundary grid points to the interior of the relaxation region (i.e., fiftieth grid point from the boundary in our case). Lateral boundary nudging allows the interior of the model to evolve relatively freely while capturing the large-scale evolution of the BSISO event. The top boundary nudging scheme applies a linearly increasing nudging time scale from the user defined time scale at the top of the model to infinity at the bottom of the relaxation layer (i.e., $20 \mathrm{~km}$ in our case). The top boundary nudging mitigates the reflection of wave energy into lower model levels. Central nudging is only applied to the soil moisture and soil temperature, and is performed on a $1-\mathrm{h}$ time scale.

\section{b. Observational data}

Results from the control simulation are validated against TRMM 3B42, version 7, and Integrated Multisatellite Retrievals for Global Precipitation Mission (GPM; IMERG), version 5B, rainfall estimates. Both TRMM 3B42 and IMERG rainfall estimates are based on multiple microwave and infrared satellite retrievals and rain gauge observations (Huffman and Bolvin 2018; Huffman et al. 2007, 2018). Though some observational inputs are the same among TRMM 3B42 and IMERG, each contain unique observation sources that are not in the other product (Table 1 of Liu 2016). TRMM 3 B42 rainfall is 3 hourly on a $0.25^{\circ} \times 0.25^{\circ}$ grid from $50^{\circ} \mathrm{S}$ to $50^{\circ} \mathrm{N}$, while IMERG produces estimates every $30 \mathrm{~min}$ on a $0.1^{\circ} \times$ $0.1^{\circ}$ grid from $90^{\circ} \mathrm{S}$ to $90^{\circ} \mathrm{N}$ (Huffman and Bolvin 2018; Huffman et al. 2018).

\section{c. BSISO event}

The bimodal ISO index (Kikuchi et al. 2012) was used to select a BSISO event to simulate. The bimodal ISO 
index identifies eight BSISO phases (i.e., spatial and temporal locations of convection) based on an extended empirical orthogonal function analysis of 25-90-dayfiltered outgoing longwave radiation (OLR) from $30^{\circ} \mathrm{S}$ to $30^{\circ} \mathrm{N}$. Phase-space diagrams of the first two leading principal components (PCs) indicate the strength and location of BSISO precipitation (e.g., Fig. 2a). We selected the July-August 2016 BSISO event because it had a strong (i.e., amplitude $>1$ ) bimodal ISO index through all BSISO phases (Fig. 2a). Also, longitude-time and latitude-time plots of IMERG precipitation over the Indian Ocean and west Pacific $\left(20^{\circ} \mathrm{S}-20^{\circ} \mathrm{N}, 45^{\circ} \mathrm{E}-180^{\circ}\right)$ show canonical BSISO eastward and northward propagation of precipitation (Figs. 2b,c). While there are other strong, canonical BSISO events, the 2016 event falls within the ERA5 time period of availability (i.e., 2008-present) and is simulated by other modeling groups (e.g., Toms et al. 2019), which will facilitate model comparisons. All simulations were started on 12 July 2016 and run through 19 August 2016 with the first day excluded from analysis, to capture a full BSISO event.

\section{Model fidelity}

Figure 3 shows time-longitude and time-latitude diagrams of surface precipitation in the model domain area for IMERG observation (left panels) and the true topography run (right panels). Both observations and the model show relatively suppressed precipitation conditions in July compared to relatively active precipitation conditions in August. Domain-mean precipitation plotted in Fig. 4 for both IMERG and TRMM 3B42 observations and each model run show a similar time distinction between active and suppressed conditions with domain-mean precipitation about twice as large during BSISO phases 5-8 (i.e., 31 July-19 August) compared to phases 1-4 (i.e., 13-30 July). We therefore classify BSISO phases 1-4 as suppressed conditions and phases $5-8$ as active conditions in our domain, which is similar to what OLR anomalies in Kikuchi et al. (2012) and Lee et al. (2013) showed for convective activity over Luzon (their Figs. 8b and 9, respectively).

During suppressed conditions, precipitation is mainly focused over Luzon and the surrounding Philippine Sea (Figs. 3a,b, east of the $122.25^{\circ}$ dashed line), especially in the model. The exceptions are two westward-propagating precipitation features at the end of July (20-21 and 24-25 July) that the model captures well. The DCP during suppressed conditions is generally stronger and more regular in the model compared to observations (Figs. 3 and 4). We speculate that the stronger and more regular precipitation in the model versus observations during the suppressed conditions may be related to the model not fully resolving convective updrafts and entrainment, which could lead to excessive rainfall that initiates and decays more quickly than reality (discussed more below). Definitively explaining model-observation differences, though, are beyond the scope of this paper. From 29 July to 1 August a tropical cyclone (TC) moves northwestward from the Philippine Sea to the north coast of Luzon (Fig. 3) and explains the large precipitation at this time in the domain-mean precipitation plot (Fig. 4).

During active conditions, there is eastward (Figs. 3a,b) and northward (Figs. 3c,d) propagation of precipitation from 5 to 18 August in both observations and the true topography run. However, the model shows less precipitation over the SCS and more precipitation over Luzon than the IMERG observations (Figs. 3a,b). Domain mean precipitation during this time is slightly underestimated by the model compared to the observations. Overall, though, the model captures the evolution and strength of the BSISO event well with a domain mean precipitation (Fig. 4) root-mean-square error (RMSE) of $0.17 \mathrm{~mm} \mathrm{~h}^{-1}$ between the true topography run and IMERG and $0.27 \mathrm{~mm} \mathrm{~h}^{-1}$ between the true topography run and TRMM, which is less than and slightly above, respectively, the RMSE of $0.19 \mathrm{~mm} \mathrm{~h}^{-1}$ between TRMM and IMERG. We therefore have confidence to utilize RAMS for sensitivity experiments to discern the effects of topography on the DCP over Luzon during different BSISO phases.

\section{DCP: Control versus sensitivity runs}

Figure 4 shows that the DC of the domain-mean precipitation is visible throughout the entire BSISO event for all three model simulations. At the 3-hourly time scale shown in Fig. 4, the DCP amplitude (i.e., daily maximum minus minimum precipitation) is more regular during suppressed conditions versus active conditions. Specifically, the variance of the DCP amplitude is 3-4 times smaller during suppressed conditions than active conditions. Also noticeable is the general increase in domain-mean precipitation as topography increases (Fig. 4). During suppressed conditions, the time- and space-mean precipitation increases as topography increases. During active conditions, the time- and spacemean precipitation is largest in the doubled topography run, but larger in the flat versus true topography run. If the domain is segregated by land and ocean, the time and space mean over land increases as topography increases regardless of large-scale BSISO condition. Land versus ocean differences are discussed more below.

The mean DCP illustrates the differences among the three simulations more clearly than the domain-mean precipitation plot (cf. Figs. 5 and 4). The mean DCP was 
b) IMERG Longitude-Time

(a) BSISO 2016

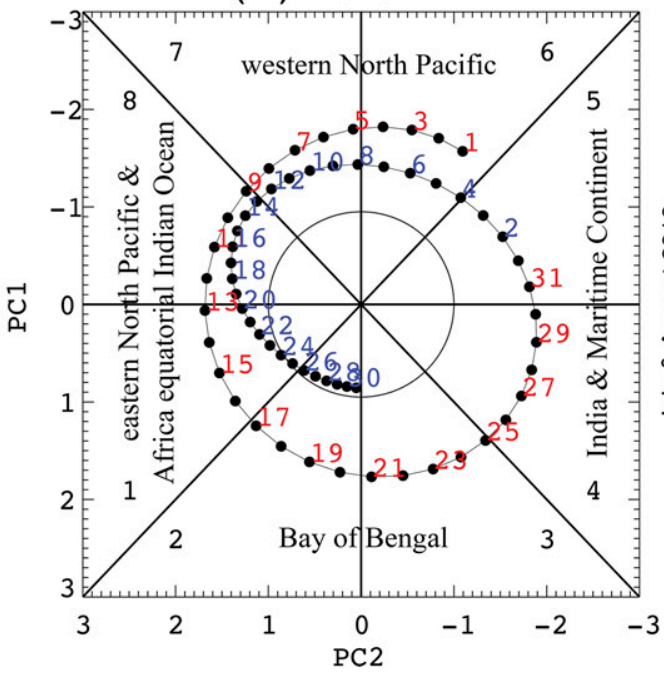

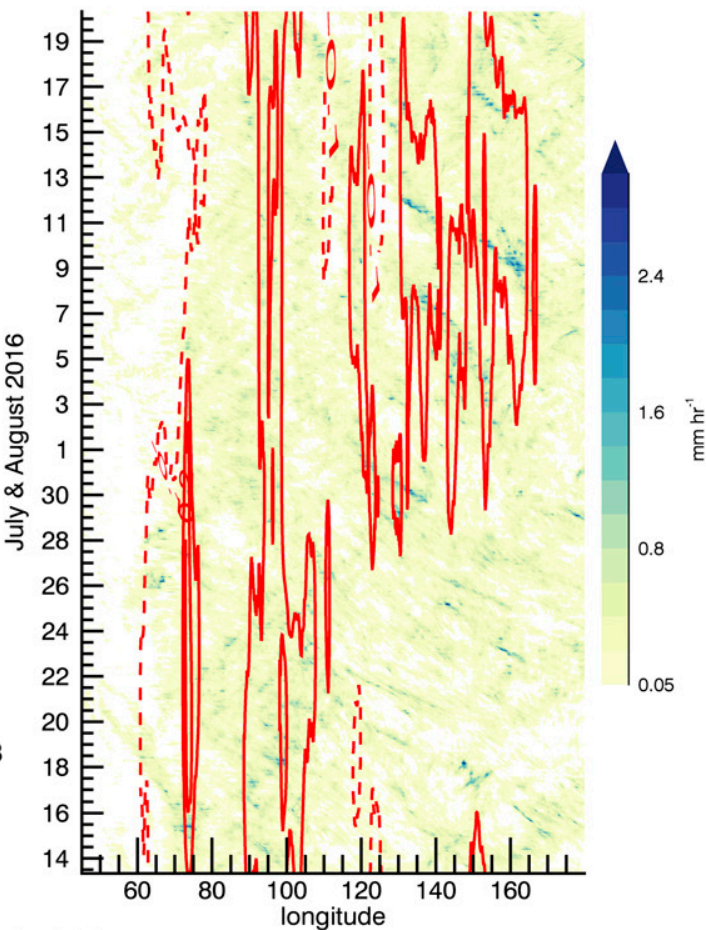

c) IMERG Latitude-Time

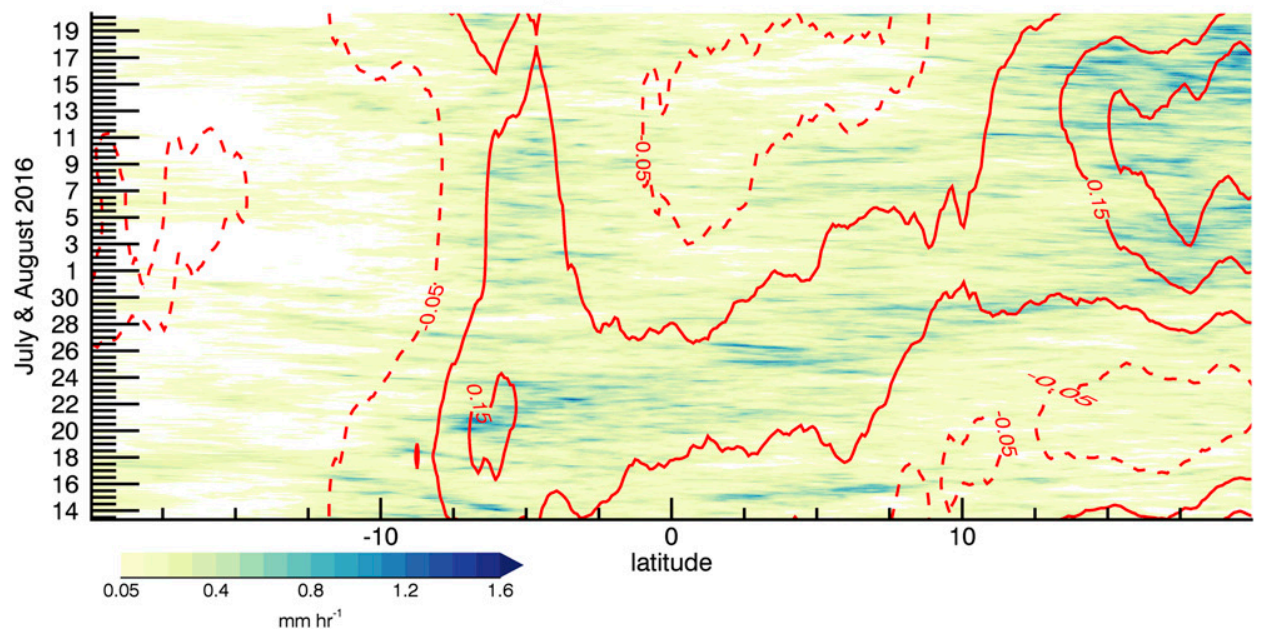

FIG. 2. (a) Bimodal intraseasonal oscillation index (Kikuchi et al. 2012) phases from July to August 2016. Redand blue-colored numbers correspond to July and August, respectively. Note that only every other day is numbered for clarity. (b) Time-longitude diagram of IMERG precipitation averaged over $20^{\circ} \mathrm{S}-20^{\circ} \mathrm{N}$. (c) Time-latitude diagram of IMERG precipitation averaged over $45^{\circ} \mathrm{E}-180^{\circ}$. Red contours indicate $20+$ day filtered anomalies. Positive anomalies are solid, while negative anomalies are dashed. For (b) and (c), time has been adjusted to local time.

computed similarly to that of Yokoi et al. (2017) by making composites of precipitation for each 30-min time increment during the day. Diurnal harmonic analysis gave similar results as the composite approach (not shown). DC composites of precipitation were made for land versus ocean during suppressed and active conditions separately (Fig. 5).
The mean DCP from IMERG and TRMM is included in Fig. 5 for observation-model comparison. Table 1 provides the RMSE of the mean DCP for each BSISO large-scale condition over land versus ocean between the true topography run and IMERG and TRMM, separately, and between IMERG and TRMM. Except for during the active phase over the ocean, the model-observation 
a) IMERG longitude-time precipitation

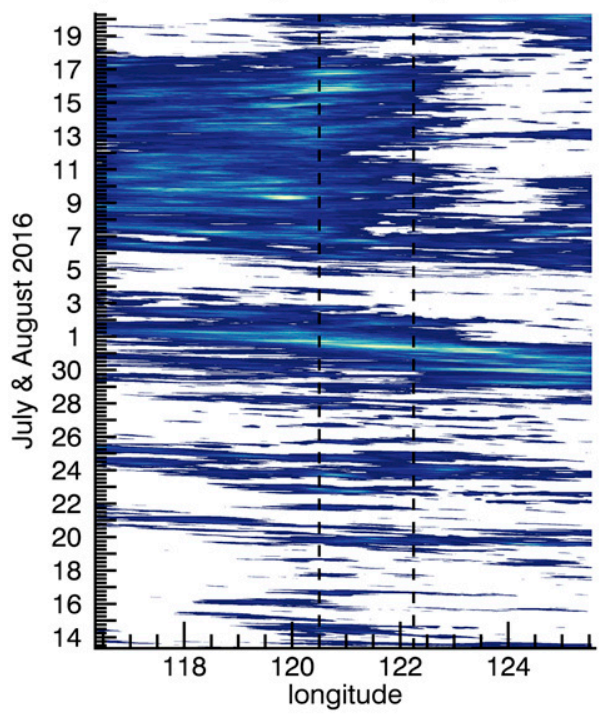

c) IMERG latitude-time precipitation

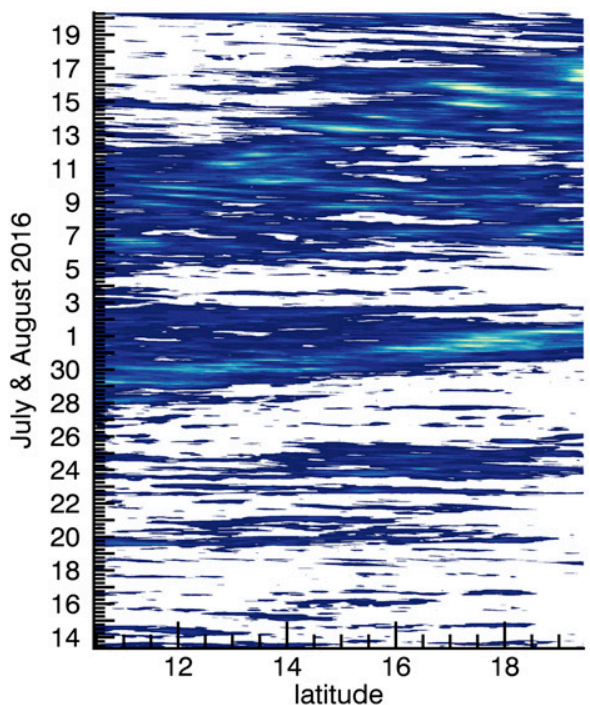

b) RAMS True Topo. longitude-time precipitation

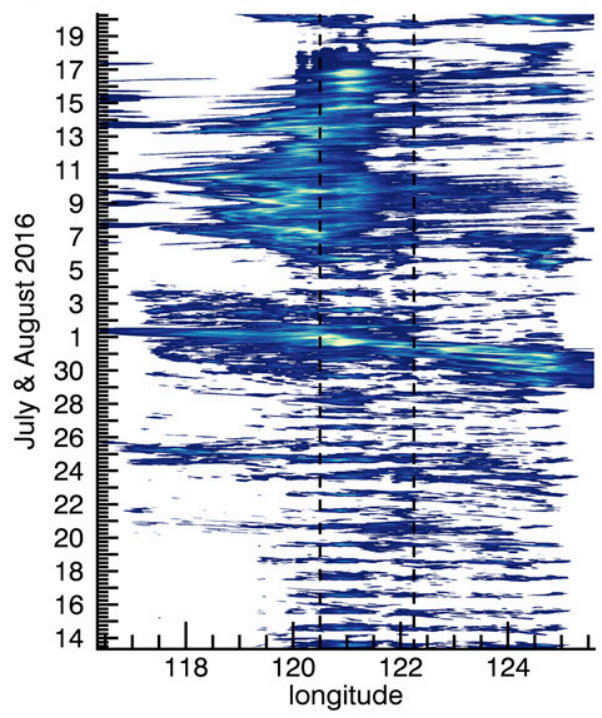

d) RAMS True Topo. latitude-time precipitation

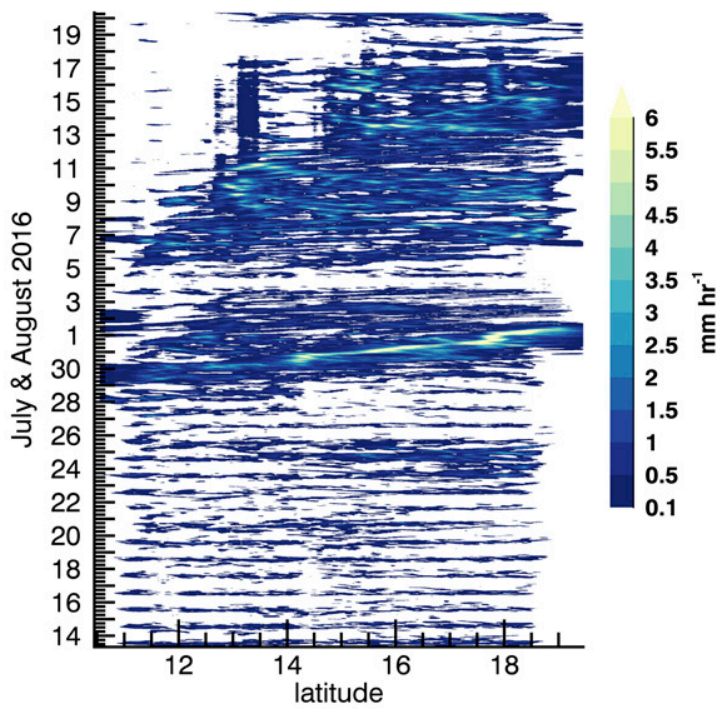

FIG. 3. (top) Time-longitude diagrams of surface precipitation for the model domain longitudes averaged over (a) the model domain latitudes for IMERG and (b) the RAMS true topography run. (bottom) Time-latitude diagrams of surface precipitation for the model domain latitudes averaged over (c) the model domain longitudes for IMERG and (d) the RAMS true topography run. Time is in local time. The dashed black lines in (a) and (b) indicate the approximate locations of northern Luzon's east and west coasts. The true topography run has been averaged to the $0.1^{\circ}$ IMERG resolution. The color bar applies to all panels.

RMSE is larger than the IMERG-TRMM RMSE. Over land, model precipitation is generally overestimated with an earlier afternoon peak compared to observations (Figs. 5a,c). During suppressed conditions over land, the mean DC peak for the true topography run is $1.23 \mathrm{~mm} \mathrm{~h}^{-1}$ at $1430 \mathrm{LT}$, while the mean DC peaks for IMERG and TRMM are $0.77 \mathrm{~mm} \mathrm{~h}^{-1}$ at $1730 \mathrm{LT}$ and $0.745 \mathrm{~mm} \mathrm{~h}^{-1}$ at $1700 \mathrm{LT}$, respectively (Fig. 5a). Similarly, during active conditions over land, the mean DC peak for the true topography run is $1-1.5 \mathrm{~h}$ earlier and 1.6 and 2.3 times larger than the IMERG and TRMM mean DC peak, respectively (Fig. 5c). The model overestimation of precipitation over land could be exaggerated because IMERG may underestimate true surface precipitation over land (e.g., Wang et al. 2018; Kim et al. 2017) and TRMM 3B42 is known to underestimate precipitation over high terrain (e.g., Scheel et al. 2011; Matthews et al. 2013; Rasmussen et al. 2013). Hassim et al. (2016) and 


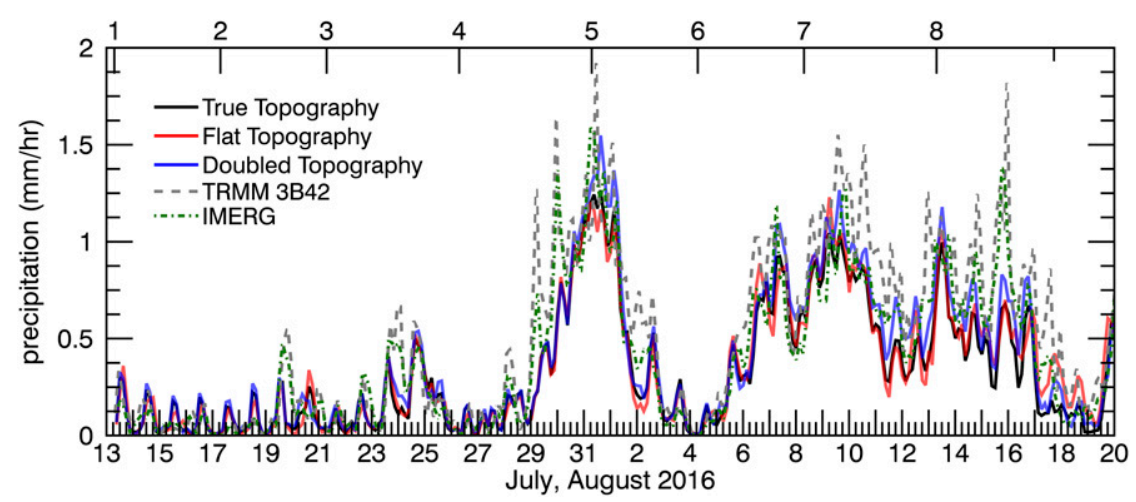

FIG. 4. Model domain-mean surface precipitation for the RAMS true topography run (black), flat run (red), and doubled topography run (blue), as well as TRMM 3B42 (dashed gray) and IMERG (dashed-dotted green) observations. The top axis indicates the start time (LT) of each BSISO phase. IMERG and the three RAMS runs were averaged to the TRMM 3B42 3-hourly time scale.

Vincent and Lane (2016) also showed an earlier (by 3-4h) and more intense peak in the DCP in their 4-km cloud-resolving Weather Research and Forecasting (WRF) Model simulations over New Guinea compared to TRMM 3B42 observations. Hassim et al. (2016) postulated that their model-observation intensity discrepancy was due to the inability of their WRF simulation to adequately resolve convective updrafts and topography. Their simulated clouds were too wide and did not entrain enough, leading to excessive rainfall compared to observations. The $2-\mathrm{km}$ grid spacing used here is perhaps still too coarse to fully resolve convective updrafts and entrainment since Bryan et al. (2003) and Del Genio and Wu (2010) showed that the development of deep convection in CRMs is sensitive to grid spacing down to $0(100) \mathrm{m}$. The inability to fully resolve convective updrafts and entrainment could also explain the earlier DCP peak in the model compared to observations since the transition from shallow-to-deep convection is sensitive to entrainment rate (e.g., Del Genio and Wu 2010; Stirling and Stratton 2012). Despite the model-observation timing difference in the mean DCP peak, the model and observations both demonstrate a single afternoon peak that has a similar start time to the ramp up of afternoon precipitation (i.e., near 1000 LT; Figs. 5a,c).

Over the ocean during suppressed conditions, both model and observations show three peaks in precipitation though the timing of the peaks differ between the model and observations (Fig. 5b). Over the ocean during active conditions, the model and IMERG show a relatively flat progression of precipitation, while TRMM has a midday and overnight peak (Fig. 5d). Over the ocean, RAMS underestimates precipitation compared to observations. However, TRMM 3B42 overestimates precipitation over the ocean when compared to rain gauges on buoys (e.g., Wu and Wang 2019). Likewise, in the tropical Pacific, IMERG overestimates precipitation compared to buoys, but in the Indian Ocean comparison of IMERG and buoy precipitation vary based on buoy location. Model biases in precipitation compared to the satellite observations may be inflated given the biases in the satellite versus surface observations.

Definitively explaining the model-observation timing and intensity differences is beyond the scope of this paper. For the objective of this paper-to understand the effects of topography on the DCP over Luzon in different BSISO large-scale conditions-the RAMS simulations are sufficient because they show how the simulated DCP changes with the removal or enhancement of topography relative to the realistic topography simulation and RAMS correctly captures the evolution of the BSISO from suppressed to active conditions and its northeastward propagation (Fig. 4).

\section{a. Mean oceanic DCP}

Over the ocean, the mean DCP during both active and suppressed conditions is muted in terms of distinct diurnal peaks and amplitude relative to the DC over land, which is consistent with previous studies (e.g., Nesbitt and Zipser 2003; Liu and Zipser 2008; Sakaeda et al. 2017). The lack of a DC over ocean is especially true during active conditions where the DCP is essentially flat (Fig. 5d). The blending of the SCS and Philippine Sea precipitation in the composite of ocean precipitation explains why during the active conditions the flat and doubled topography runs show higher precipitation than the true topography run (Fig. $5 \mathrm{~d}$ ). The location of precipitation during active conditions shifts depending on the topographic height. As topography increases, more 
a) Land: Suppressed Conditions

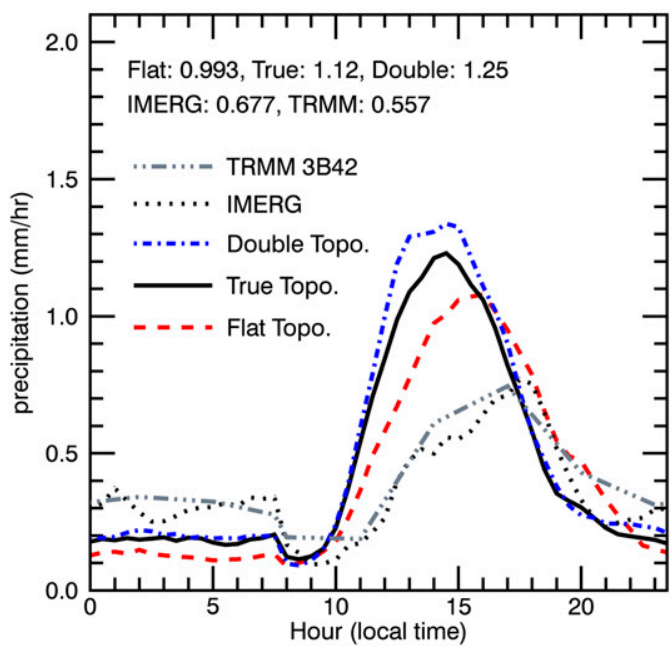

c) Land: Active Conditions

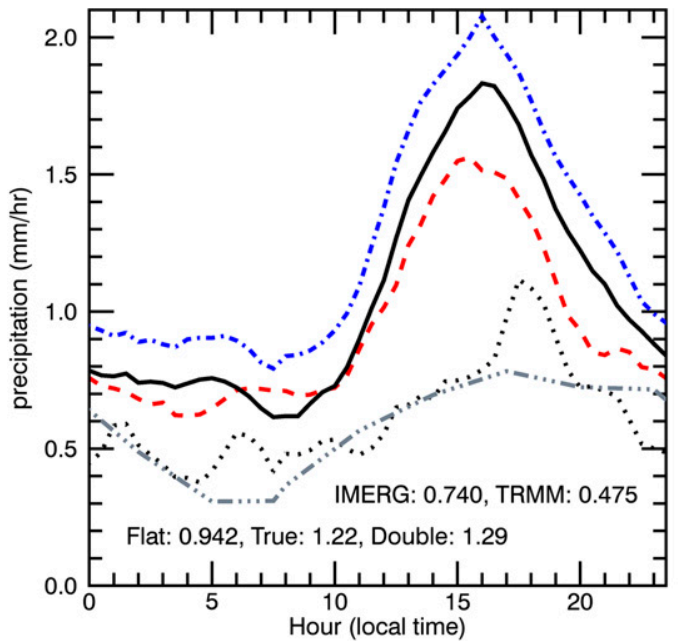

b) Ocean: Suppressed Conditions

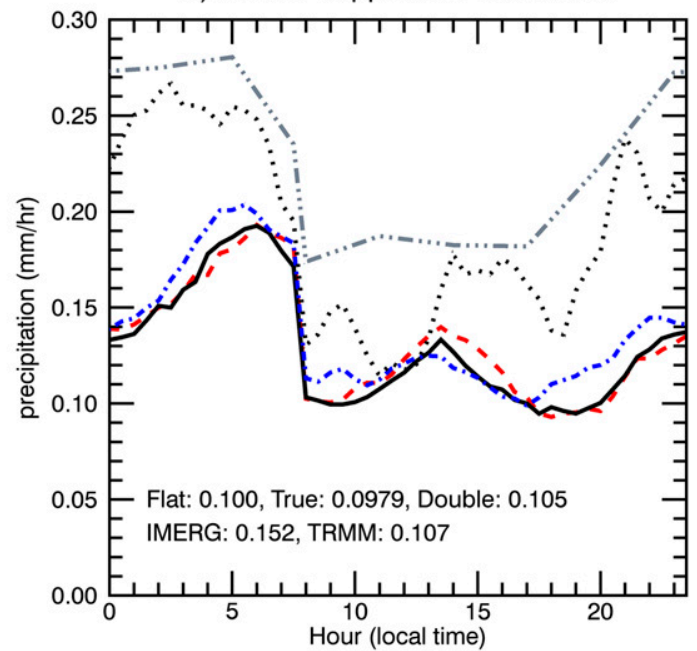

d) Ocean: Active Conditions

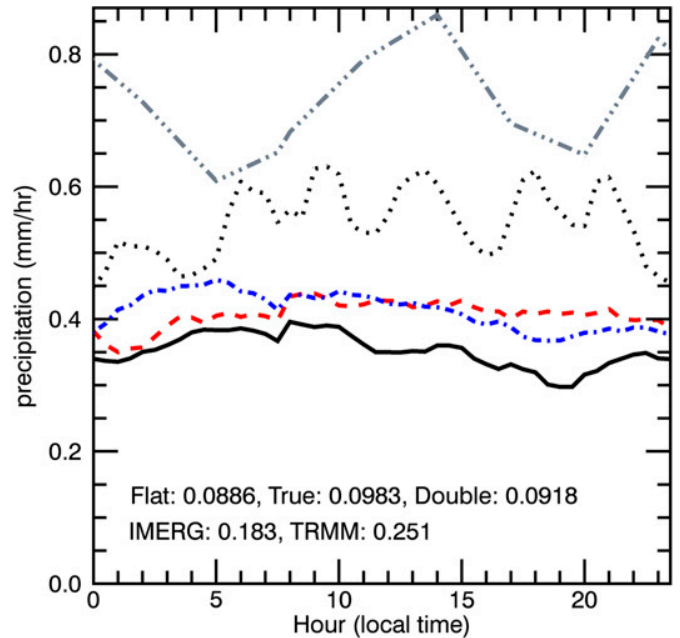

FIG. 5. The mean diurnal cycle of surface precipitation for the true topography (solid black), flat (dashed red), and doubled topography (dashed-dotted blue) runs, as well as, IMERG (dotted black) and TRMM 3B42 (dashdot-dot gray) for (top) suppressed conditions over (a) land and (b) ocean and (bottom) active conditions over (c) land and (d) ocean. The amplitude as measured by maximum minus minimum mean DCP value for each run and observational dataset is indicated in each panel.

rain preferentially falls over the SCS compared to the Philippine Sea (Fig. 6). Reasons for the shift in precipitation location during active conditions are discussed below. During suppressed conditions, the mean DCP over the ocean has two peaks in all runs: an early morning (0500-0600 LT) and midday (1300 LT) peak (Fig. 5b). These peaks occur slightly earlier as topography increases. However, there is no systematic difference in

TABLE 1. Root-mean-square error of the mean DCP ( $\mathrm{mm} \mathrm{h}^{-1}$; i.e., Fig. 5) between the RAMS true topography run (RAMS for short) and IMERG, between RAMS and TRMM, and between IMERG and TRMM for the suppressed BSISO conditions over land and ocean separately and for the active BSISO conditions over land and ocean separately.

\begin{tabular}{lcccc}
\hline \hline & Suppressed, land & Suppressed, ocean & Active, land & Active, ocean \\
\hline RAMS - IMERG & 0.30 & 0.069 & 0.51 & 0.20 \\
RAMS - TRMM & 0.28 & 0.099 & 0.56 & 0.38 \\
IMERG - TRMM & 0.068 & 0.040 & 0.13 & 0.20 \\
\hline
\end{tabular}




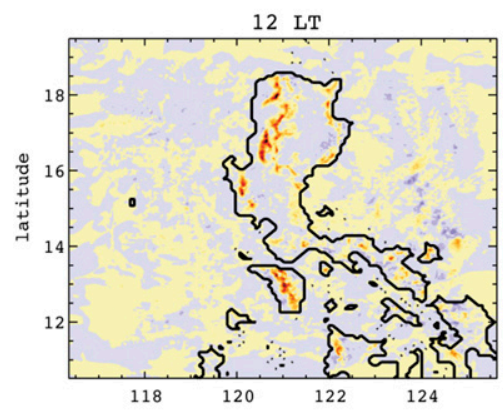

a) Suppressed Conditions
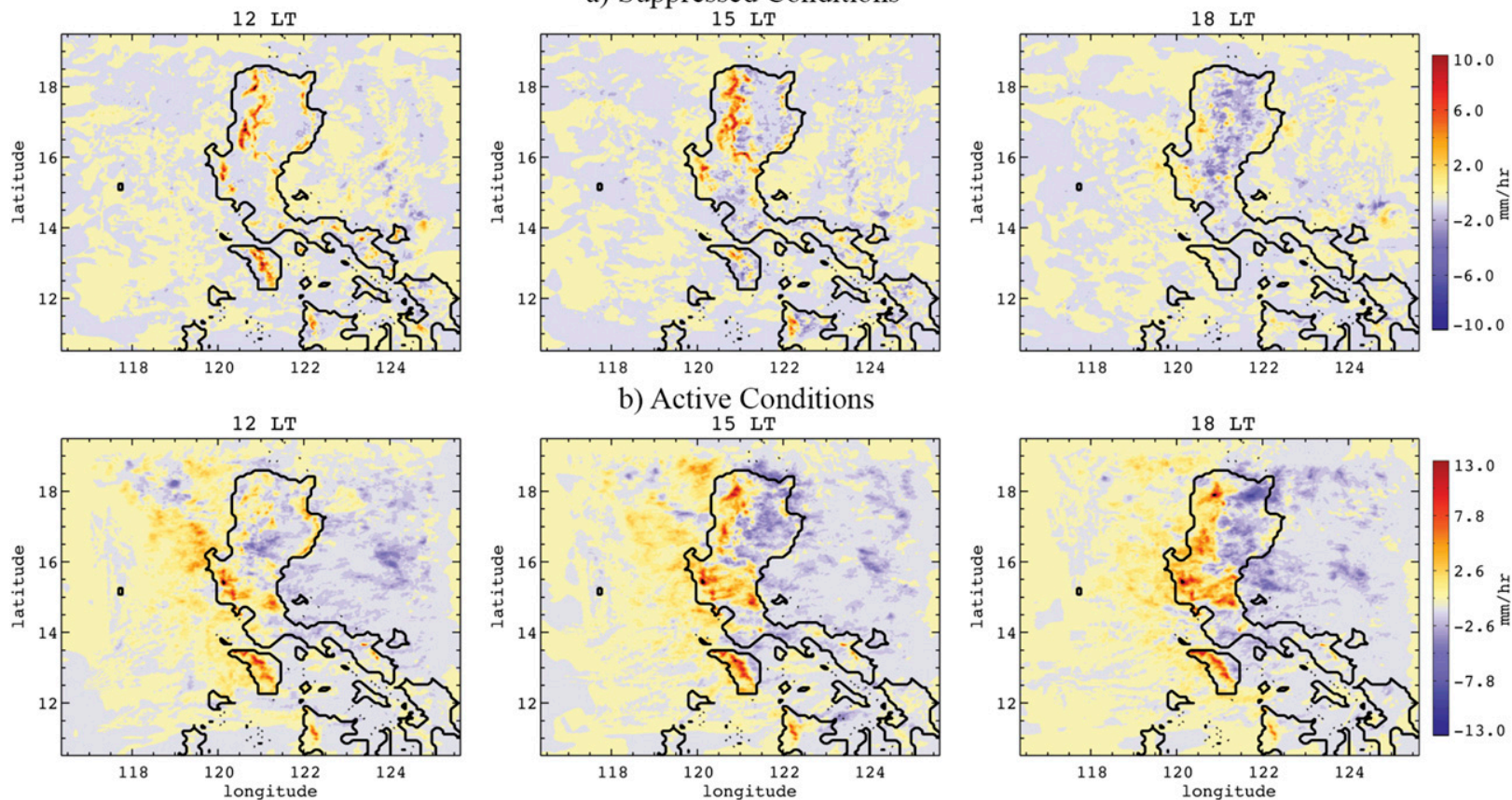

FIG. 6. The difference in surface precipitation between the doubled topography run and flat run during (a) suppressed and (b) active BSISO conditions for 3-hourly averaged time bins centered on (left) 1200, (center) 1500, and (right) 1800 LT.

the magnitude of the mean DCP over the ocean among the three runs (Fig. 5b) even when composites are made separately for the SCS and Philippine Sea suggesting that topography has little effect on oceanic precipitation surrounding Luzon during suppressed BSISO conditions.

\section{b. Mean land DCP}

Over land for all runs and BSISO conditions, the mean DCP has one afternoon peak (1430-1600 LT; Figs. 5a,c). Both the magnitude and amplitude of the afternoon mean DCP peak over land are larger during active versus suppressed conditions for each respective run, with the exception of the flat run amplitude, which decreases from suppressed to active conditions (cf. Figs. 5a,c). Specifically, during suppressed conditions the mean DCP peaks are $1.08,1.23$, and $1.34 \mathrm{~mm} \mathrm{~h}^{-1}$ for the flat, true, and doubled topography runs, respectively, while during active conditions the DCP peaks for those same respective runs are $1.56,1.83$, and $2.08 \mathrm{~mm} \mathrm{~h}^{-1}$ (Figs. 5a,c). Amplitudes of the mean DCP are given in each panel of Fig. 5. Active conditions relative to suppressed conditions in the elevated topography runs have a later (i.e., 1600 vs 1430 LT; Table 2) and broader mean DCP peak (i.e., 7.5 and $8 \mathrm{~h}$ vs 6.5 and $5.5 \mathrm{~h}$ for the true and doubled runs, respectively; cf. Figs. 5a,c and Table 3) and slightly slower transition to peak afternoon precipitation (Table 2). The DCP width was measured as the full width at half the maximum height of the
Gaussian distribution of the DCP. Rauniyar and Walsh (2011) also noted a 1-2-h delay in the DCP over the MC during active $\mathrm{MJO}$ conditions relative to suppressed MJO conditions based on TRMM 3B42 and 3G68 observations of boreal winter from 1998 to 2008. In contrast to the elevated topography runs, the flat run mean DCP during active versus suppressed conditions is slightly earlier (i.e., 1530 vs 1600 LT; Table 2) and narrower (i.e., $6.5 \mathrm{vs} 7 \mathrm{~h}$; Table 3 ).

Within a specified BSISO condition (i.e., suppressed or active) over land, the mean DCP peak and amplitude increase as topography increases (Figs. 5a,c). During suppressed conditions over land, the flat run transitions from minimum to maximum precipitation slower than the true and doubled topography runs (i.e., 8 vs $6 \mathrm{~h}$, respectively; Table 2) and has a delayed (i.e., 1600 vs 1430 LT, respectively; Table 2) and wider mean DC peak relative to the elevated topography runs (Fig. 5a and Tables 2 and 3). The opposite is true during active conditions over land; precipitation in the flat run transitions from minimum to maximum faster than the elevated topography runs (i.e., 6 vs $8.5 \mathrm{~h}$, respectively; Table 2) and has a slightly earlier (i.e., 1530 vs 1600 LT, respectively) and narrower mean DCP peak relative to the true and doubled topography runs (Fig. 5c and Tables 2 and 3). Barthlott and Kirshbaum (2013) found a delayed DCP peak when topography was flat versus realistic in their CRM simulations over two Mediterranean 
TABLE 2. Times (LT) of minimum and maximum precipitation in the mean DCP over land for suppressed (i.e., BSISO phases 1-4) and active (i.e., BSISO phases 5-8) conditions.

\begin{tabular}{llccc}
\hline \hline Condition & & Flat run & $\begin{array}{c}\text { True topography } \\
\text { run }\end{array}$ & $\begin{array}{c}\text { Doubled } \\
\text { topography run }\end{array}$ \\
\hline Suppressed & Min & 0800 & 0830 & 0830 \\
& Max & 1600 & 1430 & 1430 \\
Active & Min & 0400 & 0730 & 0730 \\
& Max & 1530 & 1600 & 1600 \\
\hline
\end{tabular}

islands for a 26 August 2009 case study. However, Qian (2008) found an earlier DC peak when topography over Java was flat versus realistic in their model simulations of 30 years (1971-2000) of boreal winters. Qian (2008) used cumulus parameterization (i.e., the Emanuel-Massachusetts Institute of Technology cumulus scheme; Emanuel and Živković-Rothman 1999) for subgrid-scale cumulus convection in their 25-km-grid-space simulations, which could explain the DC timing difference between their simulation and ours, as well as with those of Barthlott and Kirshbaum (2013), both of which used explicitly resolved convection. The significance of these two works to our study is unclear given that neither work examined the topographic effects on the DCP for various largescale ISO conditions. Nevertheless, the works are relevant because both note timing differences in the DCP peak due to topography changes.

\section{c. Geographical distribution of the DCP}

In active conditions compared to suppressed conditions, the precipitation is more widespread over both land and ocean (cf. Figs. S1-S3 to Figs. S4-S6 in the online supplemental material). However, within each large-scale condition, topography helps dictate the location of precipitation. Figure 6 shows the spatial differences for the doubled topography and flat runs in 3-hourly averaged precipitation bins for times centered on 1200, 1500, and $1800 \mathrm{LT}$ during the suppressed (Fig. 6a) and active (Fig. 6b) conditions. We only show these three time periods for conciseness. These times also encompass the majority of the evolution of the afternoon land DCP peak (i.e., 1030-1930 LT; Figs. 5a,c) and thus represent the most identifying differences among the runs. Only doubled topography minus flat run differences are shown since they represent the extreme dichotomy in elevation between the three runs. Precipitation differences between the true topography and flat runs and doubled minus true topography runs show similar results to Fig. 6.

During suppressed conditions, the presence of elevated topography focuses precipitation over the coastal mountains during the afternoon as indicated by the positive precipitation values in Fig. 6a where mountains are located (Fig. 1). By contrast, the flat run has more precipitation in the interior of Luzon than the doubled topography run. As in the mean DCP composites (Fig. 5), a DCP phase difference during suppressed conditions is noticeable between the two runs; positive precipitation differences peak one time bin ahead of the peak negative precipitation differences (i.e., Fig. 6a; 1500 vs 1800 LT, respectively). Overnight into morning (i.e., 0000-0900 LT) shows an opposite signal with more surface precipitation in the interior of Luzon in the doubled topography run relative to the flat run (not shown).

During active conditions, topography primarily dictates which side of Luzon the rain preferentially falls on (Fig. 6b). More rain falls over the SCS and western side of Luzon in the doubled topography run compared to more rain over the Philippine Sea and eastern side of Luzon in the flat run. Similar to the suppressed conditions, the doubled topography run has increased precipitation over mountain regions regardless of island side, especially during the 1200 LT time bin. These findings are valid for all times of the day. The geographical distribution of the absolute values of precipitation for each run and large-scale condition are provided as Figs. S1-S6 to emphasize the location, intensity, and timing differences of the DCP as topography increases.

\section{d. Summary of control versus sensitivity experiments of the DCP}

Collectively, the differences in the mean DCP across the three runs indicate that topography helps to dictate the timing, strength, and duration of the DCP, especially over land versus ocean (Figs. 4 and 5 and Tables 2 and 3 ). From suppressed to active conditions over land, the presence of elevated topography (i.e., true and doubled

TABLE 3. Width of mean DCP peak over land measured as the full width at half maximum for suppressed (i.e., BSISO phases 1-4) and active (i.e., BSISO phases 5-8) conditions.

\begin{tabular}{llccr}
\hline \hline Condition & & Flat run & True topography run & Doubled topography run \\
\hline Suppressed & Range (LT) & $1200-1900$ & $1100-1730$ & $1130-1700$ \\
\multirow{2}{*}{ Active } & Duration (h) & 7 & 6.5 & 5.5 \\
& Range (LT) & $1230-1900$ & $1230-2000$ & $1200-2000$ \\
\hline
\end{tabular}


topography) induces a later, broader, and slightly largeramplitude afternoon peak than would otherwise occur in the absence of elevated topography (i.e., flat topography; Figs. 5a,c and Tables 2 and 3). Within each largescale condition over land, as topography increases, the peak and amplitude of the mean DCP increases. During suppressed conditions over land, the flat run's mean DCP peak is delayed relative to the true and doubled topography mean DCP peaks. Topography also affects the location of precipitation (Fig. 6). During suppressed conditions elevated topography focuses precipitation over the coastal mountains, while during active conditions the presence or absence of elevated topography dictates which side of the domain more rain will fall on.

\section{Understanding control versus sensitivity DC differences}

Figures in this section are restricted to northern Luzon (i.e., land north of $16.4^{\circ} \mathrm{N}$; Fig. 1). The restriction to northern Luzon ensures an easier interpretation of mesoscale circulations with respect to the mountains and coastlines in the following latitudinally averaged longitude-height cross-sectional plots, since the island and mountains in northern Luzon are oriented approximately north-south. Previous works have used similar approaches by taking section averages (e.g., Ichikawa and Yasunari 2006) or slices (e.g., Vincent and Lane 2017) across MC islands to analyze the evolution of the DC for various MC islands. Figures made with all domain latitudes were similar to the northern Luzon figures.

\section{a. Convective instability differences}

We compare convective instability using convective available potential energy (CAPE) and convective inhibition (CIN) - measures of integrated positive and negative buoyancy, respectively, for a given parcel and its environment-between the three runs to help understand DCP differences. Barthlott and Kirshbaum (2013) also looked at CAPE and CIN to understand differences in precipitation in their terrain altering experiments. Figure 7 shows the DC composite of maximum CAPE (MCAPE) and maximum CIN (MCIN) over northern Luzon land for each run and large-scale condition. MCAPE and MCIN were calculated using the WRF CAPE 2D Python code, which uses parcel temperature and moisture characteristics averaged over $500 \mathrm{~m}$ centered on the maximum potential temperature height in the lowest $3000 \mathrm{~m}$ for each grid point (Ladwig 2017). To test the robustness of the WRF CAPE 2D calculations, CAPE values on 13 July 2016 were also calculated using temperature and moisture characteristics of parcels at two different locations: 1) the surface and 2) the level of maximum potential temperature below $500 \mathrm{hPa}$. Though only one day is compared, the DC of CAPE for 13 July 2016 (not shown) has the same DC evolution as the mean DC of CAPE for suppressed BSISO conditions (Fig. 7). Despite the magnitude of CAPE varying based on CAPE calculation choice, the DC phase was the same for all three methods, which gives us confidence to use the WRF CAPE 2D scheme to evaluate CAPE and CIN differences among the three runs and across the two large-scale BSISO conditions.

MCAPE values in the flat run are $400-1000 \mathrm{~J} \mathrm{~kg}^{-1}$ larger than MCAPE values in the elevated topography runs for active and suppressed conditions (Figs. 7a,c). This large difference could be from a shallower layer of positive buoyancy in the presence of topography. Also, lower specific humidity values over elevated terrain compared to the flat terrain may reduce the available buoyancy in the elevated topography runs (not shown). Barthlott and Kirshbaum (2013) also found an inverse relationship between CAPE and terrain height, which they partially attributed to a reduction in the moisture supply to convection as topography increases. Higher CAPE values usually indicate more intense precipitation, but this is not the case here where the flat run DCP peak is lower than the elevated topography runs despite having higher MCAPE, which suggests MCAPE differences do not affect DCP intensity.

From suppressed to active conditions, the timing of the maximum MCAPE and minimum MCIN shifts to later in the day in all three runs by $1.5-2.5 \mathrm{~h}$ for MCAPE and $1-2 \mathrm{~h}$ for MCIN (Fig. 7, top vs bottom panels). The shift of maximum convective instability to later in the afternoon is consistent with the shift in the mean DCP peak to later in the afternoon in the elevated topography runs, but not in the flat run, since the flat run mean DC peak is $30 \mathrm{~min}$ earlier in the active versus suppressed conditions. Also, within each separate large-scale condition (i.e., suppressed or active), MCAPE peaks earlier in the flat run than in the true and doubled topography runs (Figs. 7a,c), while minimum MCIN in the three runs occurs simultaneously (Figs. 7b,d). These MCAPE and MCIN phase relationships within a given type of largescale condition are inconsistent with the mean DCP phase relationship, which showed a delayed mean DCP peak in the flat run relative to the true and doubled topography runs during suppressed conditions and a simultaneous mean DCP peak during active conditions. Therefore, timing differences in the peak mean DCP among the three runs for a given large-scale condition are not due to convective instability differences. 

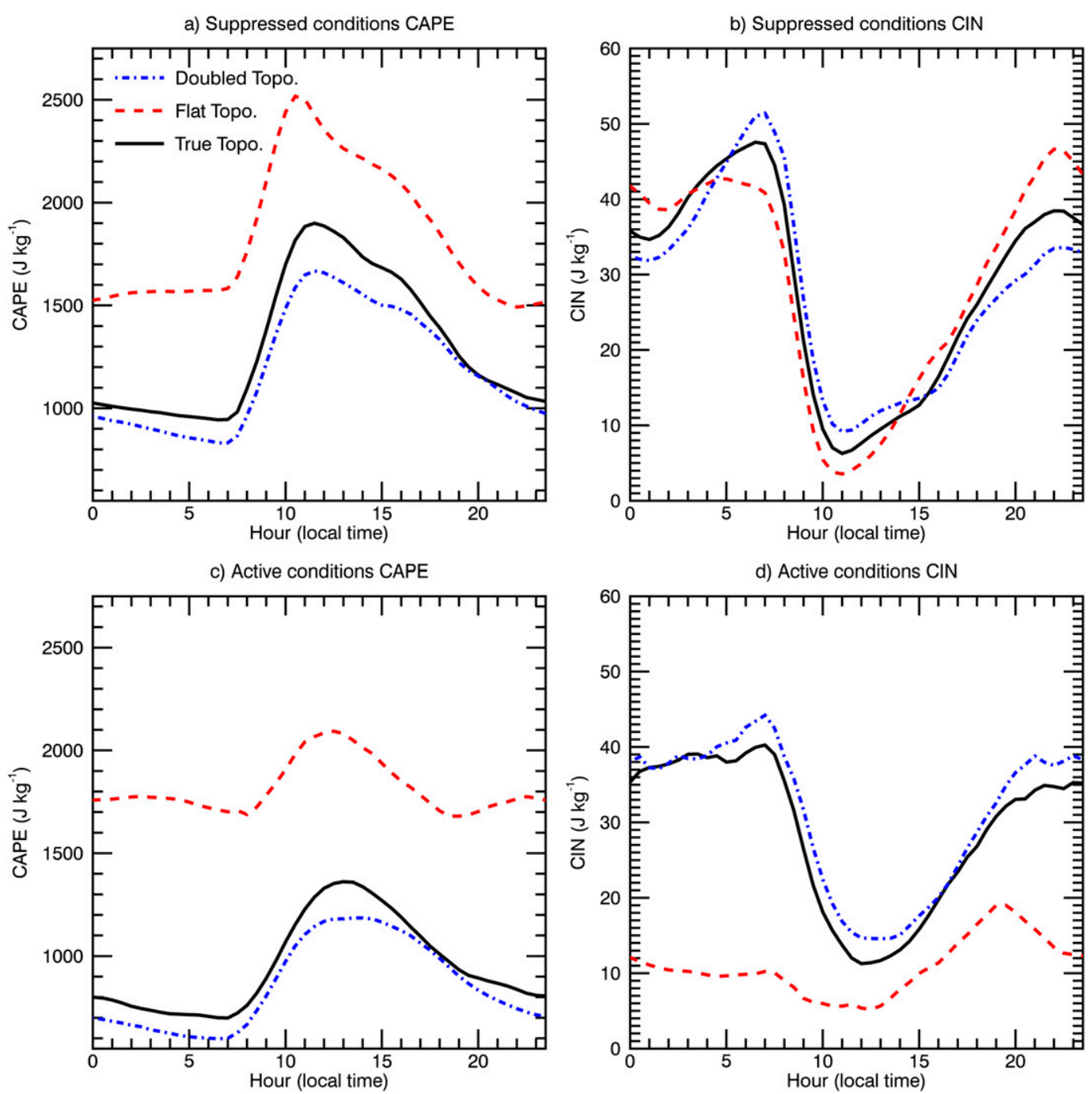

FIG. 7. (a) Diurnal cycle composite of maximum CAPE during suppressed BSISO conditions for northern Luzon land in the true topography (solid black), flat (dashed red), and doubled topography (dashed-dotted blue) runs. (b) As in (a), but for maximum CIN. (c), (d) As in (a) and (b), respectively, but for active BSISO conditions. See text for explanation of maximum CAPE and CIN.

Convective instability differences from suppressed to active conditions may influence the delay of the mean DCP peak from active to suppressed conditions in the elevated topography runs, but not the timing of the DCP peak from suppressed to active conditions in the flat run. It is unclear why in the flat run from suppressed to active conditions convective instability is inconsistent with the DCP peak shift.

Evaluation of the spatial distribution of MCIN may help explain the change in location of diurnal precipitation across the three runs. Figures S7 and S8 show longitude versus time-of-day plots over northern Luzon for the average DC of MCIN. In both large-scale conditions, the daytime reduction in MCIN over land in the flat case is more widespread inland than the true and doubled topography runs (Figs. S7 and S8). In the elevated topography runs, the reduction in MCIN is greater over the mountains compared to the valley in central northern Luzon; this is especially true during suppressed conditions (Figs. S7 and S8). These spatial distribution differences in the reduction of daytime MCIN may elucidate why precipitation in the runs that include topography are confined to high terrain, whereas the DCP in the flat run is more widespread inland. Demko and Geerts (2010) and Behrendt et al. (2011) also found that a preferential reduction of CIN over the Santa Catalina Mountains in Arizona and the Black Forest Mountains in Germany, respectively, partially accounted for the concentration of precipitation over the high terrain compared to nearby lowlands. 


\section{b. Local circulation differences}

The zonal background wind switches from easterly during suppressed conditions to westerly during active conditions (cf. Figs. 8-10 and Figs.13-15). There is also a strong southerly component to the wind during active conditions (not shown). For the entire domain, the $3-\mathrm{km}$ zonal wind averages for all three runs are -2.7 and $6.9 \mathrm{~m} \mathrm{~s}^{-1}$ during suppressed and active conditions, respectively. We chose to compare the $3-\mathrm{km}$ wind since that height is above both the topography and sea-breeze circulation for all three runs and large-scale conditions.

During suppressed conditions, daytime sea breezes occur along the west coast of northern Luzon in all three runs (Figs. 8-10). These sea breezes converge overland with easterly onshore flow from the east coast (Figs. 810). During active conditions, the main wind signal is persistent southwesterlies impinging upon Luzon. The relative strength of these circulations among the three runs in the suppressed versus active conditions offers insight to the mean DCP differences (i.e., the later and broader mean DCP in active vs suppressed conditions when there is elevated heterogeneous topography). Also, changes in the location of upward motion associated with the circulation in the various runs dictate the location of precipitation across the three runs within a given large-scale condition.

\section{1) SuPPRESSED CONDITIONS}

In suppressed conditions, the elevated topography runs compared to the flat run have a deeper sea breeze that reaches peak onshore flow earlier in the day (cf. Figs. 8-10). During the 1200 LT bin, the sea breeze along and off the west coast (i.e., onshore westerly flow) is deeper east of about $117^{\circ} \mathrm{E}$ and stronger at this time as topography increases (cf. Figs. 8-10). Also, during the 1200 LT bin, peak onshore flow (i.e., near $6 \mathrm{~m} \mathrm{~s}^{-1}$ ) along the western slope of the western mountain (i.e., near $120.5^{\circ} \mathrm{E}$ ) commences in the elevated topography runs, but is delayed until the 1500 LT bin in the flat run when all three runs exhibit maximum onshore flow (as measured by the areal extent of near-peak westerlies). Coinciding with the maximum sea-breeze westerlies, all three runs achieve maximum sea-breeze height during the 1500 LT bin, though the sea breeze remains deeper in the true and doubled topography runs than in the flat run. Sea-breeze height refers to the maximum depth of the westerlies over land locations and is indicated on the 1200-1800 LT panels in Figs. 8-10. By the 1800 LT bin, both the height and strength of the sea breeze in all three runs diminishes (cf. Figs. 8-10). Interestingly though, maximum onshore flow during the 1500 and $1800 \mathrm{LT}$ bins is stronger and farther advanced inland from the western coastline in the flat (Fig. 8) versus elevated topography runs (Figs. 9-10). The stronger and fartherinland propagation of the sea breeze in the flat versus elevated topography runs during the 1500 and 1800 LT bins aligns with the enhanced surface precipitation in the interior of Luzon at this time in the flat run relative to the elevated topography runs (Fig. 6a). Also, the seabreeze height decreases more from the 1500 to $1800 \mathrm{LT}$ bin in the runs with versus without elevated topography (cf. Figs. 8-10). The sea-breeze height reduction from 1500 to $1800 \mathrm{LT}$ is $231 \mathrm{~m}$ in the flat run, while it is 514 and $724 \mathrm{~m}$ in the true and doubled topography runs, respectively. Therefore, while the absolute height of the sea breeze is still deeper in the elevated topography runs relative to the flat run at $1800 \mathrm{LT}$, the sea-breeze strength (as measured by the depth of the sea breeze) has weakened relatively more in the elevated topography runs by 1800 LT compared to the flat run. The persistence of the sea-breeze strength in the flat topography run relative to the elevated topography runs is perhaps evidence for the wider DCP peak in the flat run versus elevated topography runs. Precipitation in the flat run is sustained longer at its peak intensity (Tables 2 and 3) because the sea breeze remains relatively stronger longer when compared to the runs with elevated topography.

The deeper, stronger sea breeze that reaches peak onshore flow earlier in the day in the elevated topography runs versus flat run is accompanied by enhanced easterly flow from the east coast in the elevated topography runs due to upslope valley-to-mountain flow. The three panels in Figs. 8b, 9b, and 10b show the 1200, 1500, and $1800 \mathrm{LT}$ potential temperature anomalies from the daily mean of each respective run. Only the 1200-1800 LT bins are shown for conciseness. The overnight potential temperature anomalies generally mirror the daytime anomalies. In all three runs, potential temperatures are anomalously warm during the day over land with maximum positive values at $1500 \mathrm{LT}$ near $121.5^{\circ} \mathrm{E}$ (Figs. 8b-10b). However, the elevated topography runs have elevated positive potential temperature anomalies along the eastern slope of the western mountain in the 1200 LT bin (Figs. 8b and 9b). Figure 11 highlights the potential temperature differences between the elevated topography and flat runs by showing the 3-hourly northern Luzon potential temperature difference between the doubled and flat topography runs for the lowest $5 \mathrm{~km}$ averaged over suppressed-condition days. For brevity, only the doubled topography minus flat difference is shown to represent the extreme potential temperature differences among the three runs. During the daytime, potential temperature is initially warmer in the doubled topography run along all the mountain locations (i.e., 0900 and 1200 LT bins). "Mountain locations" is used to 
a) Zonal wind with $\{u, w\}$-vectors
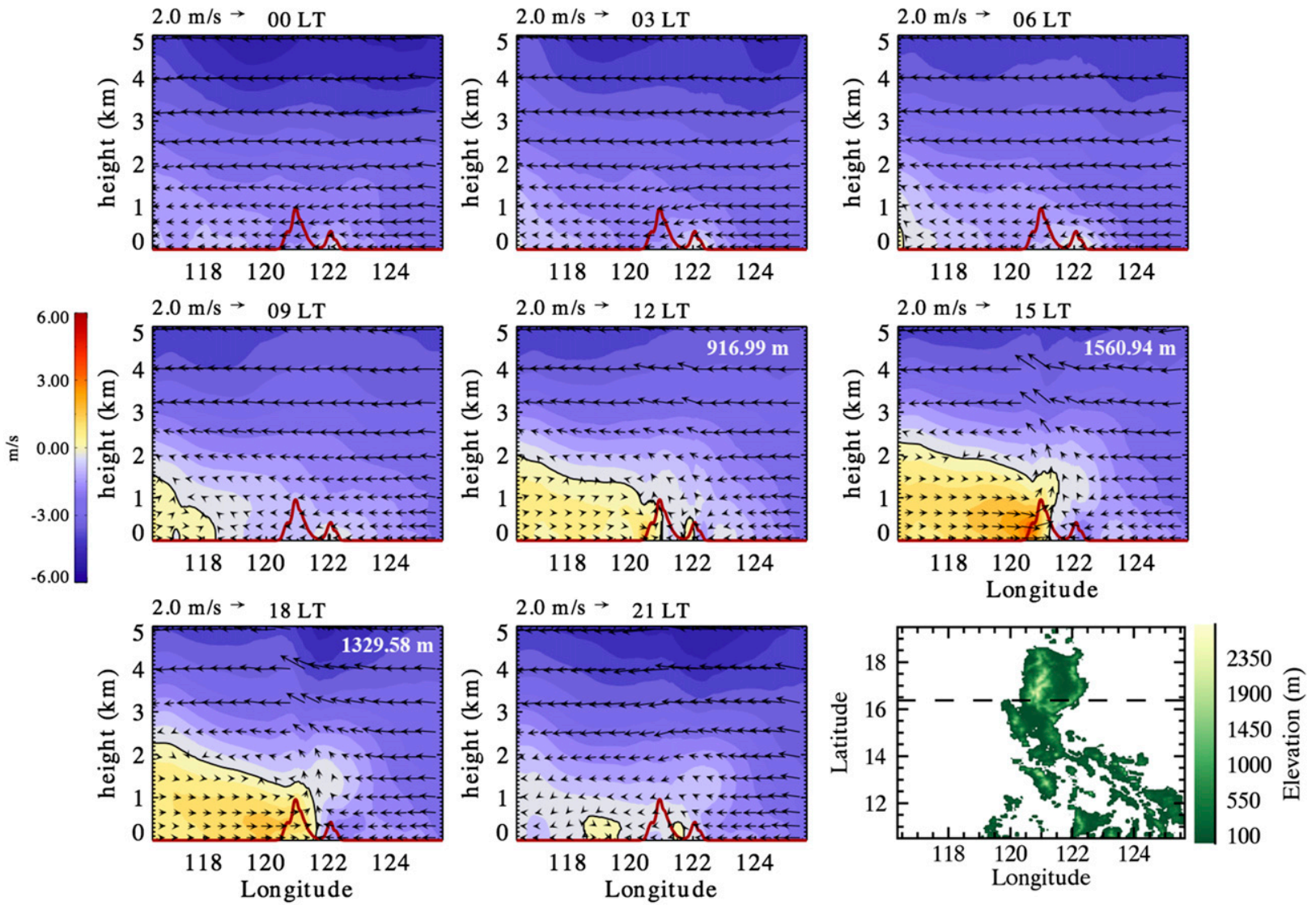

b) Potential temperature Anomalies
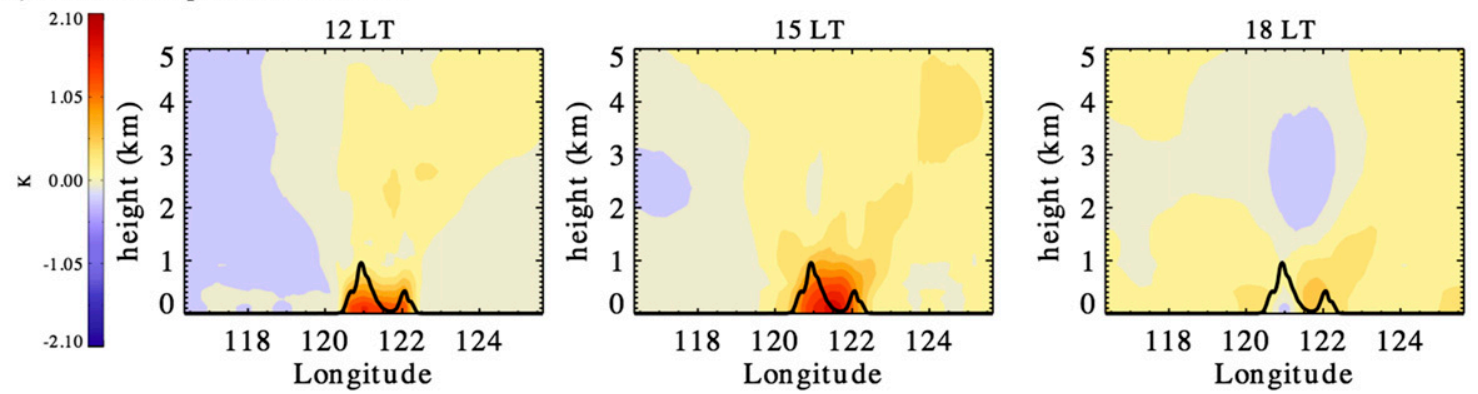

FIG. 8. (a) The flat run zonal wind (colored shading) and $\{u, w\}$ wind (vectors) averaged over northern Luzon during suppressed BSISO conditions for 3-hourly averaged time bins. Because it is impossible to plot the wind vectors at the native model grid spacing, wind vectors shown are from averaging over every 25 grid points (i.e., $50 \mathrm{~km}$ ) and every other height. In each panel, the black line is the $0 \mathrm{~m} \mathrm{~s}^{-1} \mathrm{zonal}$ wind. (a) (bottom right) Model domain with the true topography overlaid. The area north of the dashed line is defined as northern Luzon. Vertical velocities have been multiplied by 50 for clarity. The height of the sea breeze over land is included in the upper-right corner of the 1200, 1500, and 1800 LT panels of (a). (b) Potential temperature anomalies over northern Luzon in the flat run from daily mean values over northern Luzon in the flat run at each model level for the (left) 1200, (center) 1500, and (right) 1800 LT 3-hourly bin. The red and black solid lines in (a) and (b), respectively, indicate the hypothetical location of the mountains in the flat run by outlining the average northern Luzon topography from the true topography run. The temporal center of each time bin is indicated above each panel in (a) and (b).

indicate where the mountains actually are in the true and doubled topography runs, and where they hypothetically would be in the flat topography run. During the $1200 \mathrm{LT}$ bin, enhanced potential temperature in the doubled topography run relative to the flat run is elevated (1-2 km), especially along the eastern slope of the western mountains. At this time (1200 LT bin), convergence over the western Luzon mountain location (i.e., near $121^{\circ} \mathrm{E}$ ) commences in all three runs, but is particularly noticeable and stronger in the true and 
a) Zonal wind with $\{u, w\}$-vectors
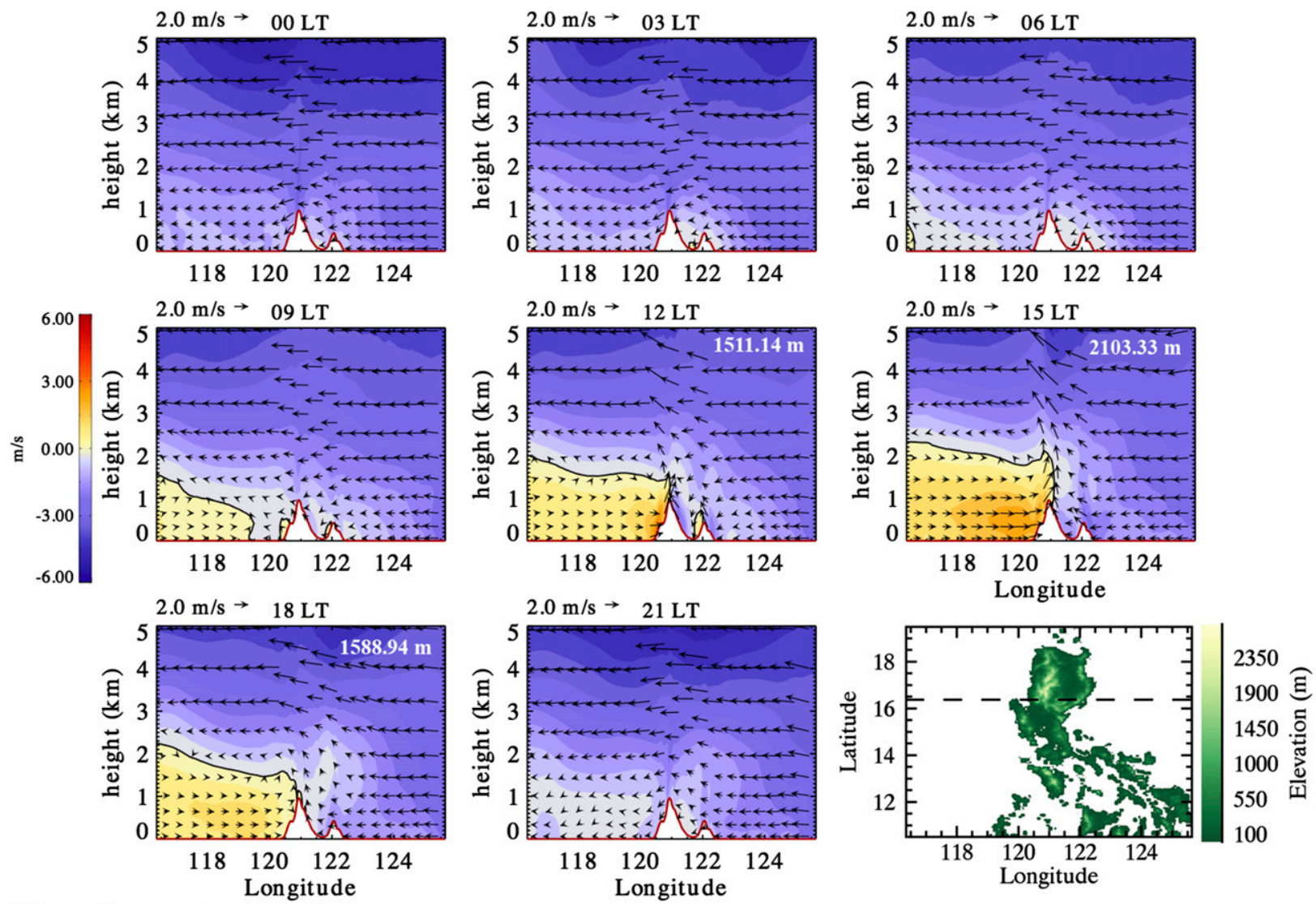

b) Potential temperature Anomalies
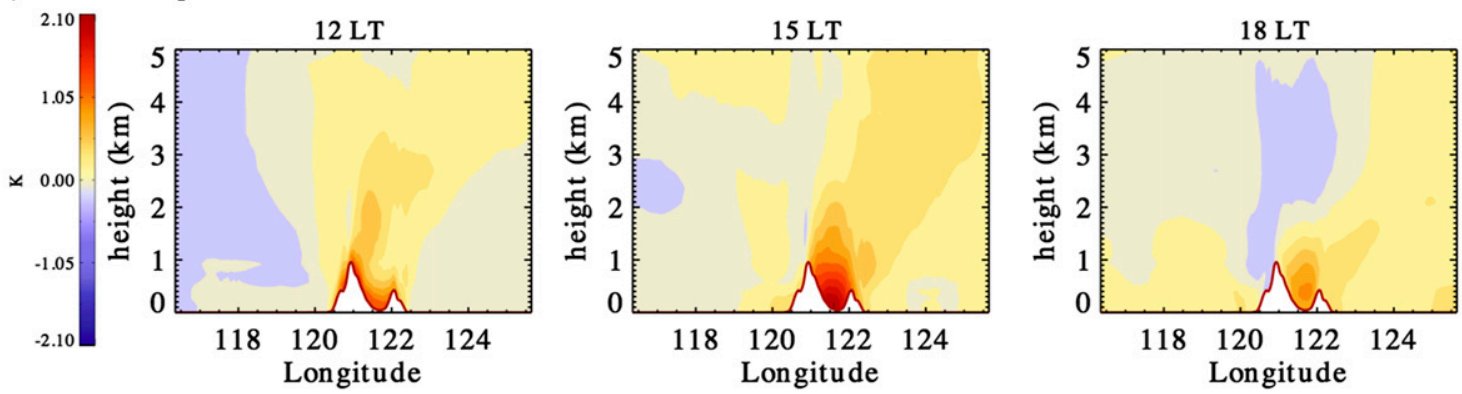

FIG. 9. As in Fig. 8, but for the true topography run and the solid red line indicates the average topography over northern Luzon for the true topography run.

doubled topography runs compared to the flat run (cf. Figs. 8-10, $\{u, w\}$ vectors). The elevated warmer potential temperature values in the doubled versus flat topography run during the 1200 LT bin likely enhance the upslope valley-to-mountain circulation via direct thermal forcing (e.g., Houze 2012; Kirshbaum et al. 2018) along the eastern slopes of the western mountains leading to stronger convergence and vertical velocities over the western mountain location in the doubled versus flat topography run. A similar process is evident to a lesser extent over the eastern slope of the eastern mountains (i.e., near $122^{\circ} \mathrm{E}$ ) with stronger upslope flow and vertical velocities over the eastern mountains from elevated warmer potential temperature values in the runs with versus without elevated topography.

As topography increases in suppressed conditions, the combination of a stronger deeper sea breeze earlier in the day (i.e., 1200 vs 1500 LT) on the western slope with a stronger upslope valley-to-mountain breeze on the eastern slope likely aids increasingly stronger convergence and precipitation earlier in the afternoon over the western mountain locations in the true and doubled 
a) Zonal wind with $\{u, w\}$-vectors
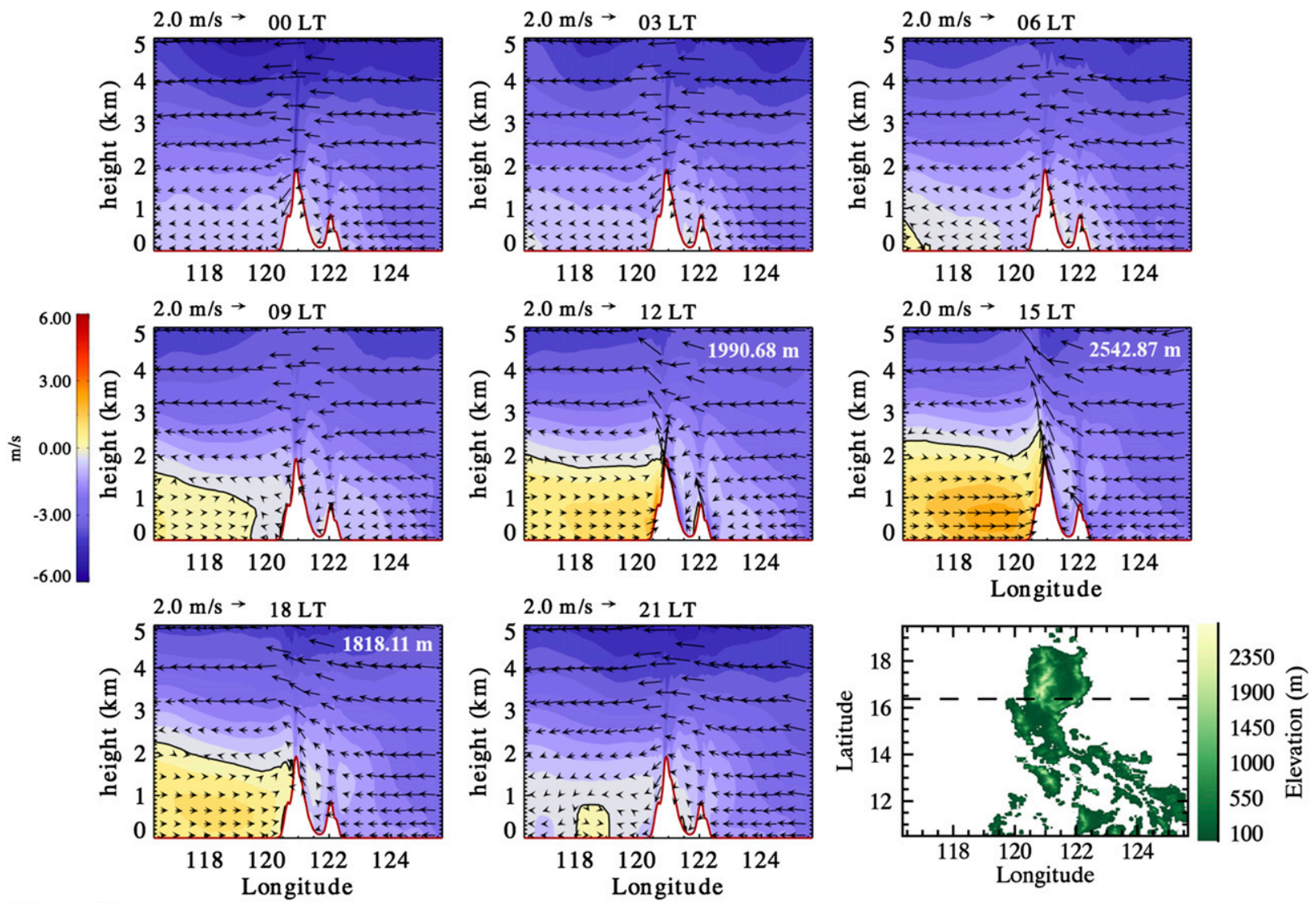

b) Potential temperature Anomalies
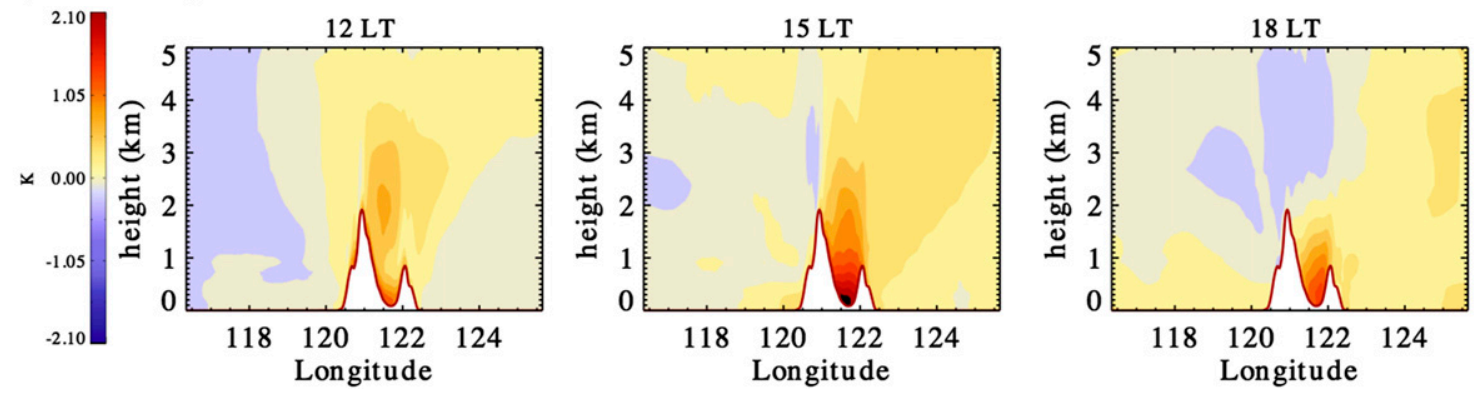

FIG. 10. As in Fig. 8, but for the doubled topography run and the solid red line indicates the average topography over northern Luzon for the doubled topography run.

versus flat topography runs (cf. Figs. 8-10). Consistent with sea-breeze and convergence changes among the three runs, moisture flux convergence over the northern Luzon western mountain locations during suppressed conditions is stronger and earlier in the elevated topography versus flat runs (not shown). Mechanical uplift is generated on the western slope of the western mountains when onshore flow encounters a boundary (i.e., the mountains) during the $1200 \mathrm{LT}$ bin in the true and doubled topography runs (Figs. 9 and 10). Simultaneously, a thermodynamically driven upslope valley-to-mountain breeze occurs on the eastern slope of the western mountains in the true and doubled topography runs from elevated warm potential temperatures (Figs. 9b, 10b, and 11). The combination of the mechanically driven and thermodynamically driven flows produces convergence over the western mountains of northern Luzon, which facilitates convective initiation. These processes start during the 1200 LT bin (Figs. 9-11) in the runs with elevated topography. In the absence of mountains in the flat run such processes are missing, which leads to weaker and delayed convergence over land (i.e., 1500 vs 1200 LT; 

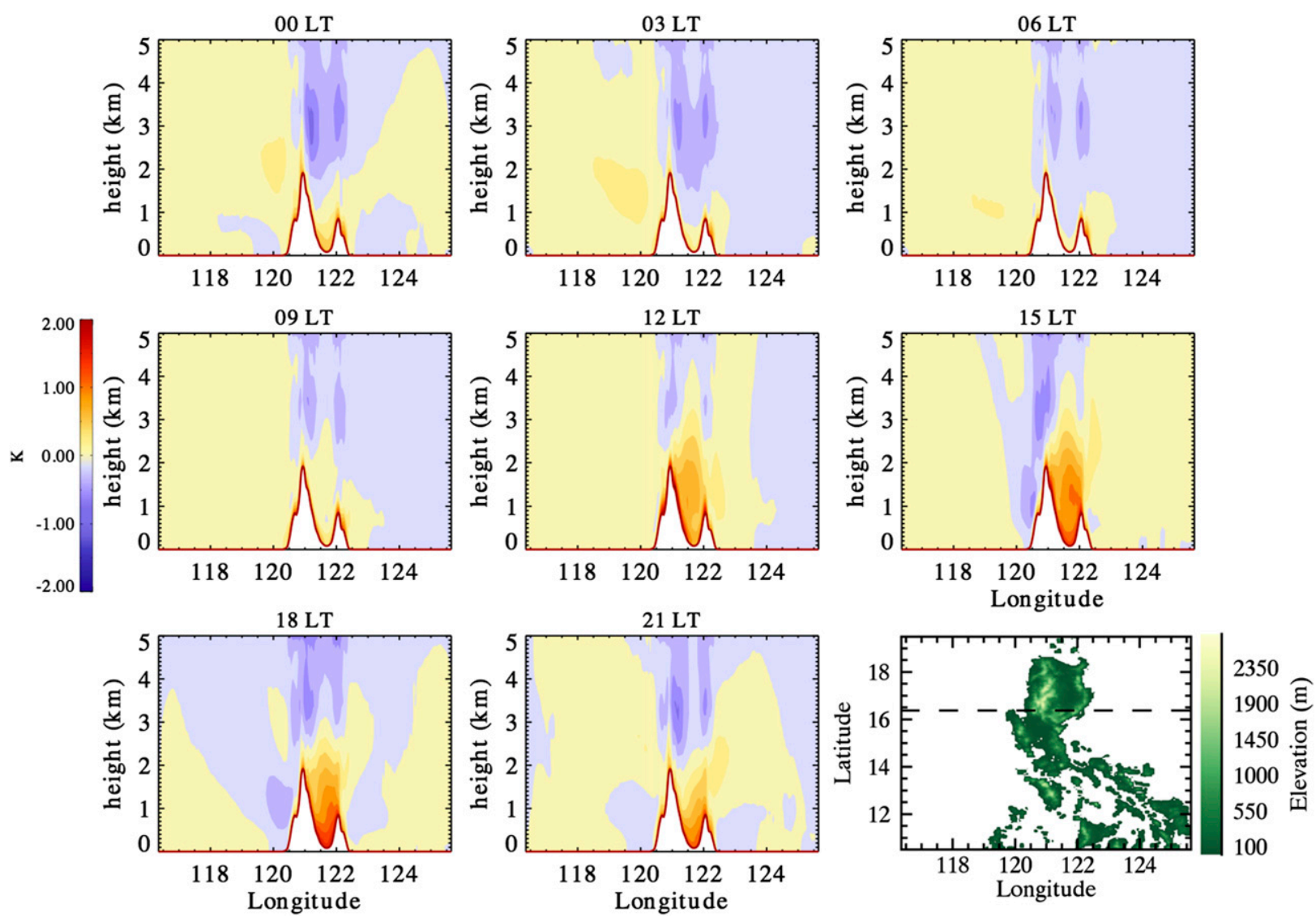

FIG. 11. Differences in potential temperature averaged over northern Luzon between the doubled topography run and flat run during suppressed BSISO conditions for 3-hourly averaged time bins. The temporal center of each time bin is indicated above each panel. The average topography over northern Luzon for the doubled topography run is indicated by the solid red line in each potential temperature panel. (bottom right) Model domain with the true topography overlaid. The area north of the black dashed line is defined as northern Luzon.

cf. Figs. 8-10) resulting in later initiation of convection and a weaker and delayed mean DCP peak relative to that in the elevated topography runs. Barthlott and Kirshbaum (2013) also discussed stronger convergence due to enhanced mechanically driven upslope flows in their simulations with higher versus lower topography to explain the earlier peak in diurnal precipitation as topography increased in their CRM simulations over two Mediterranean islands.

Evaluation of the Froude number (Fr) corroborates changes in precipitation location (Fig. 6) due to the inland extent of the sea breeze (Figs. 8-10). The Froude number helps determine whether impinging flow on a barrier (e.g., mountain) will pass over or be blocked by the barrier. It is defined as $\mathrm{Fr}=U / N H$, where $U$ is the cross-barrier flow, $N$ is the Brunt-Väisälä frequency, and $H$ is the height of the barrier. For $U$, we used the $u$ wind averaged from the approximate shoreline of northern Luzon $\left(120.3^{\circ} \mathrm{E}\right)$ to $1^{\circ}$ offshore $\left(119.3^{\circ} \mathrm{E}\right)$. Potential temperature used to compute $N$ was subject to the same averaging box as $U$. Similar to Viale et al. (2013), $H$ was defined as the height difference between the maximum northern Luzon average topography and the parcel starting height, where the parcel starting height varied from the model level closest to the surface and the model level closest to but below the maximum northern Luzon average topography. Figures 12a and $12 \mathrm{~b}$ shows the Froude number for the true and doubled topography runs during suppressed conditions. Only times when onshore zonal flow occurred at all model levels below the maximum northern Luzon average topography for the true topography runs are shown. In the true topography run, from 1130 to $1800 \mathrm{LT}$ parcels that originate just below the average maximum topography are able to pass over the northern Luzon mountains (i.e., Fr $\geq 1$ ). Additionally, parcels near the surface at 1300 LT in the true topography run can surpass the mountains (Fig. 12a). By contrast, all parcels in the doubled topography run are blocked (i.e., Fr $<1$; Fig. 12b). These changes in the Froude number are consistent with 

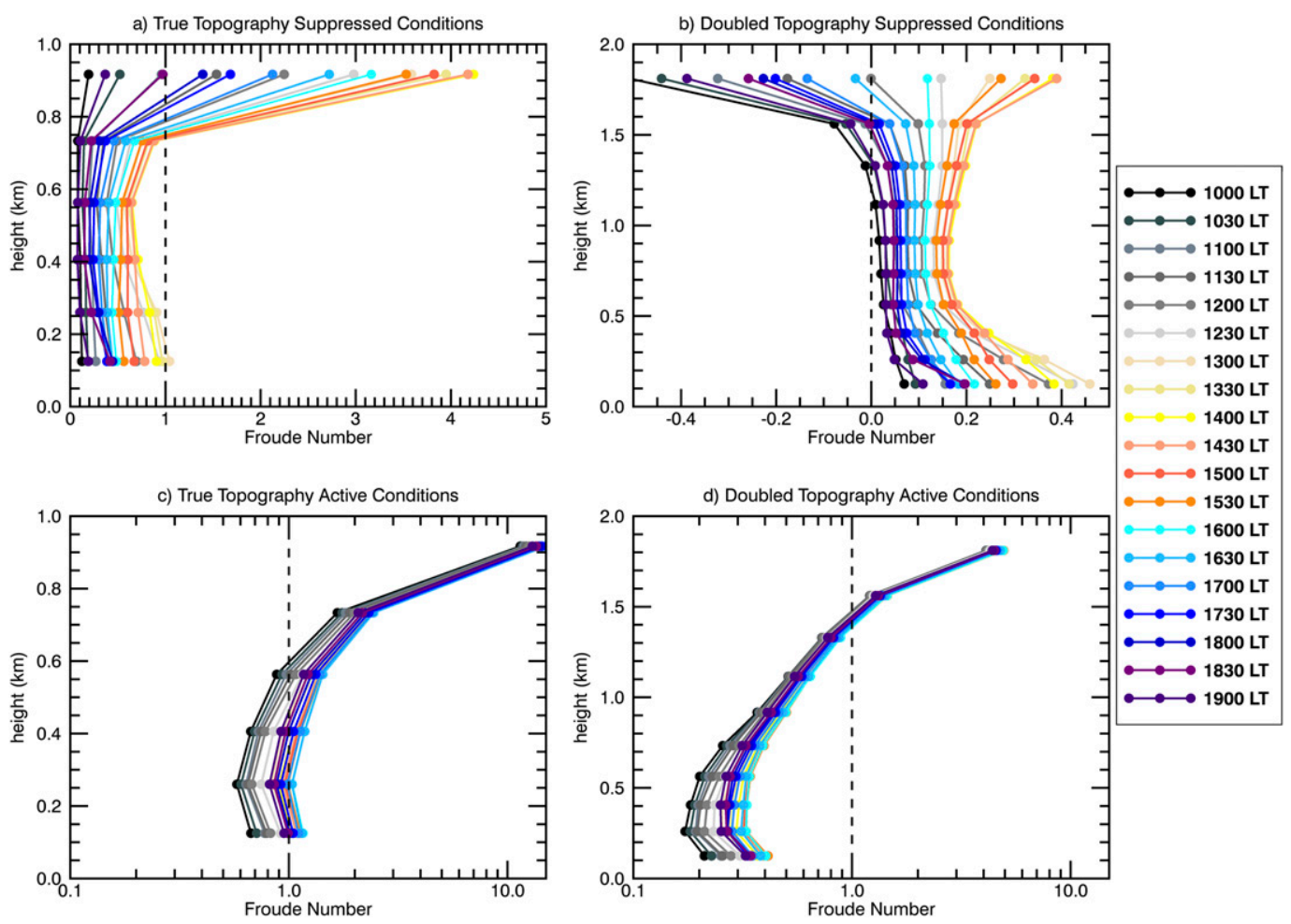

FIG. 12. Average dry Froude number $(\mathrm{Fr}=U / N H)$ for 1000 to $1900 \mathrm{LT}$ during (top) suppressed conditions for the (a) true topography run and (b) doubled topography run and (bottom) active conditions for the true (c) topography run and (d) doubled topography run. The $y$ axis of (a) and (c) goes to $1 \mathrm{~km}$, while the $y$ axis of (b) and (d) goes to $2 \mathrm{~km}$. The $x$ axis is linear in (a) and (b), but logarithmic in (c) and (d). The dashed black line indicates a dry Froude number of 1 in (a), (c), and (d), but a dry Froude number of 0 in (b). See text for details on how the Froude number was computed at model levels indicated by the colored dots.

the increased focus of precipitation over the top of the mountain ranges during the day for suppressed conditions as topography increases (i.e., Fig. 6a and Figs. S1-S3). The blocked flow in the true and doubled topography runs prevents the precipitation from crossing the mountain ranges into the northern Luzon valley. In the flat topography run where flow is not blocked, precipitation is free to propagate farther inland during the day compared to the true and doubled topography runs. This is especially noticeable later in the day at 1800 LT (Fig. 6a and Figs. S1-S3).

\section{2) Active Conditions}

During active conditions in the elevated topography runs, the mechanical forcing is still present along the western slope of the western mountains due to the strong background southwesterlies (Figs. 13a-15a), but the thermodynamically driven upslope valley-to-mountain breeze is muted (i.e., barely present only in the doubled topography run in the $1200 \mathrm{LT}$ bin; Fig. 15a) due to weaker elevated warm potential temperature anomalies relative to suppressed conditions (cf. Figs. $9 \mathrm{~b}$ and $10 \mathrm{~b}$ to
Figs. 14b and 15b). With a muted or completely absent upslope valley-to-mountain breeze in the elevated topography runs, convergence over the western mountains is lacking during active conditions. Compared to suppressed conditions, the absence of the valley-to-mountain breeze mechanism in active conditions may delay the maturation of convection to later in the afternoon and shift the mean DCP peak to later in the afternoon relative to suppressed conditions. However, once convection does mature, it can last longer due to the sustained uplift and onshore moisture transport from the persistent southwesterlies impinging on the mountains leading to the broader mean DCP peak in the active conditions relative to the suppressed conditions in the elevated topography runs. In the elevated topography runs, the duration of intense precipitation (as measured by rain rate in Figs. S1-S6) increases during active conditions relative to suppressed conditions (Figs. S2 and S3 vs Figs. S5 and S6), which also contributes to the later and broader mean DCP peak. For the true and doubled topography runs, precipitation during active conditions is equally intense in the 1500 and 1800 LT bins (Figs. S5 
a) Zonal wind with $\{u, w\}$-vectors
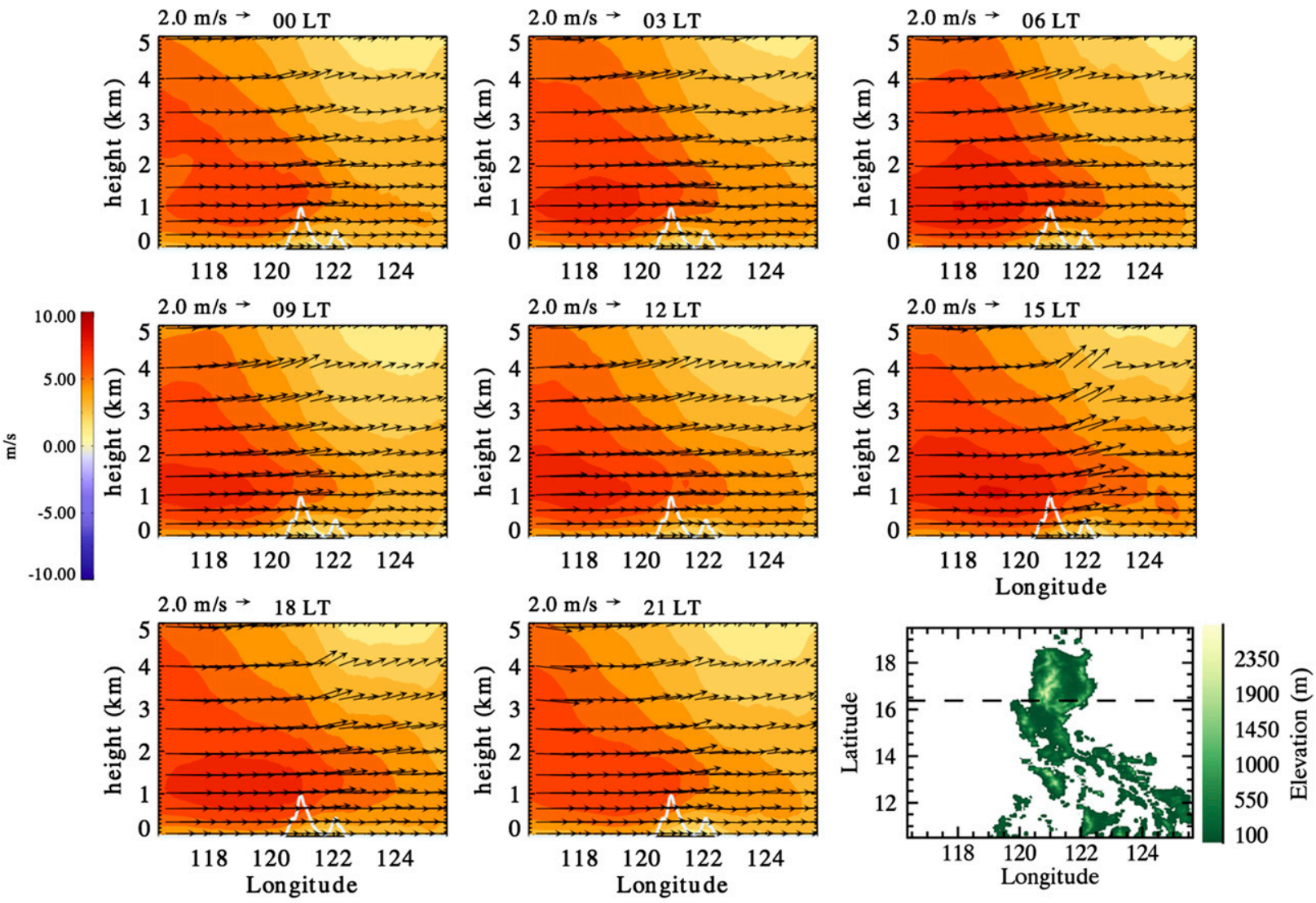

b) Potential temperature Anomalies
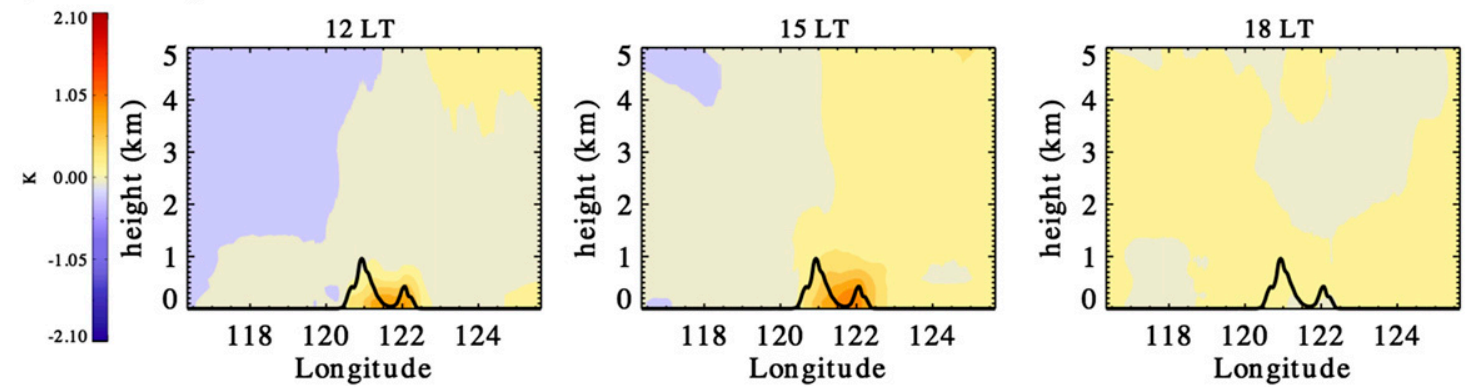

FIG. 13. (a) The flat run zonal wind (colored shading) and $\{u, w\}$ wind (vectors) averaged over northern Luzon during active BSISO conditions for 3-hourly averaged time bins. Because it is impossible to plot the wind vectors at the native model grid spacing, wind vectors shown are from averaging over every 25 grid points (i.e., $50 \mathrm{~km}$ ) and every other height. (a) (bottom right) Model domain with the true topography overlaid. The area north of the dashed line is defined as northern Luzon. Vertical velocities have been multiplied by 50 for clarity. (b) Potential temperature anomalies over northern Luzon in the flat run from daily mean values over northern Luzon in the flat run at each model level for the (left) 1200, (center) 1500, and (right) 1800 LT 3-hourly bin. The white and black solid lines in (a) and (b), respectively, indicate the hypothetical location of the mountains in the flat run by outlining the average northern Luzon topography from the true topography run. The temporal center of each time bin is indicated above each panel in (a) and (b).

and S6), whereas precipitation intensity during suppressed conditions decreases from the $1500 \mathrm{LT}$ bin to the 1800 LT bin (Figs. S2 and S3).

The flat run also has sustained westerlies during active conditions, yet the mean DCP peak occurs at about the same time as the mean DCP peak during suppressed conditions. In the absence of the mountains to provide mechanical upward ascent of parcels, maximum upward motion in the active conditions occurs during the 1500 LT bin (Fig. 13a) when maximum potential temperature anomalies near the surface over land occur (Fig. 13b), suggesting that the timing of the mean DCP 
a) Zonal wind with $\{u, w\}$-vectors
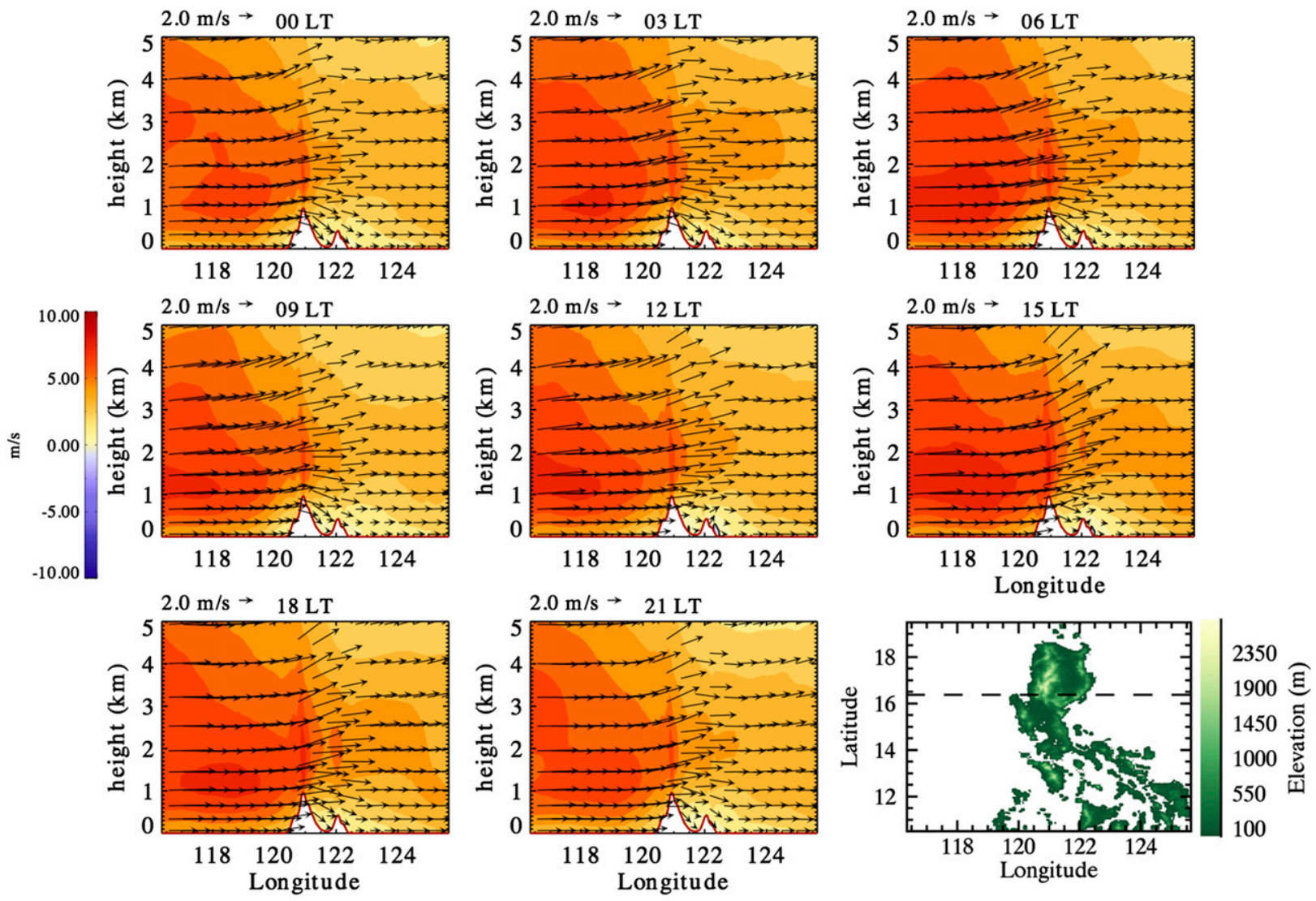

b) Potential temperature Anomalies
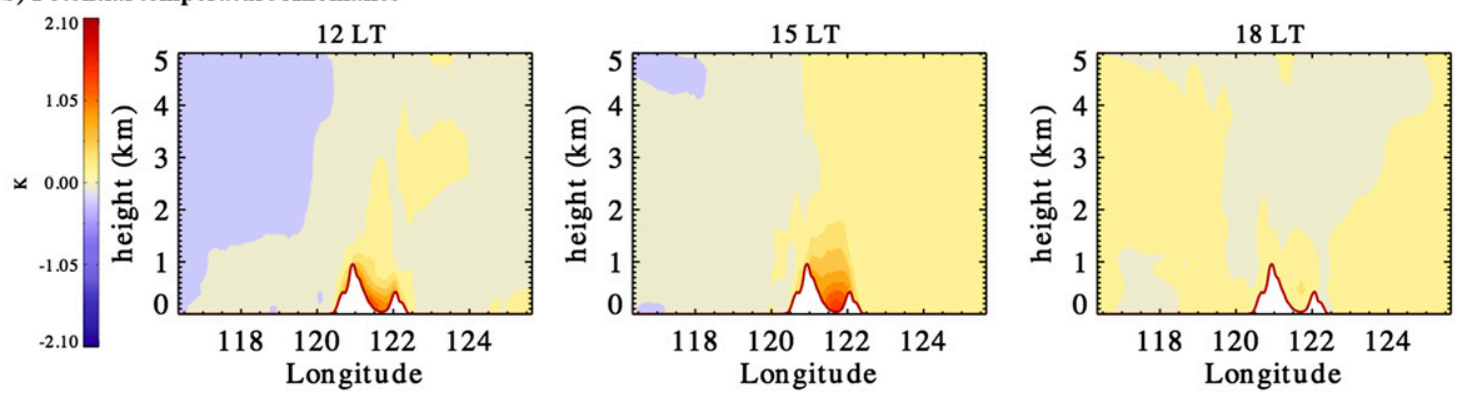

FIG. 14. As in Fig. 13, but for the true topography run and the solid red line indicates the average topography over northern Luzon for the true topography run.

peak is related to daytime heating over land. Maximum upward motion in the flat run during suppressed conditions also occurs at $1500 \mathrm{LT}$, when the west coast sea breeze is at its peak depth and collides with onshore easterly flow from the east coast. The width of the mean DCP peak in the flat run is similar for both largescale conditions because the longevity of intense precipitation in the flat run is consistent across largescale conditions with maximum intensity reached during the $1500 \mathrm{LT}$ bin and sustained through the 1800 LT bin (Figs. S1 and S4).
Changes in convective versus stratiform areal-mean precipitation were also examined to understand changes in the mean DCP peak in active versus suppressed conditions. Using observations, Sakaeda et al. (2017, 2018) found that over the Indian Ocean, west Pacific Ocean, and MC increased stratiform precipitation occurring after convective precipitation during MJO convectively enhanced conditions led to a delay in the DCP peak relative to the DCP peak in convectively suppressed conditions. For our RAMS simulations, convective versus stratiform precipitation was identified 
a) Zonal wind with $\{u, w\}$-vectors
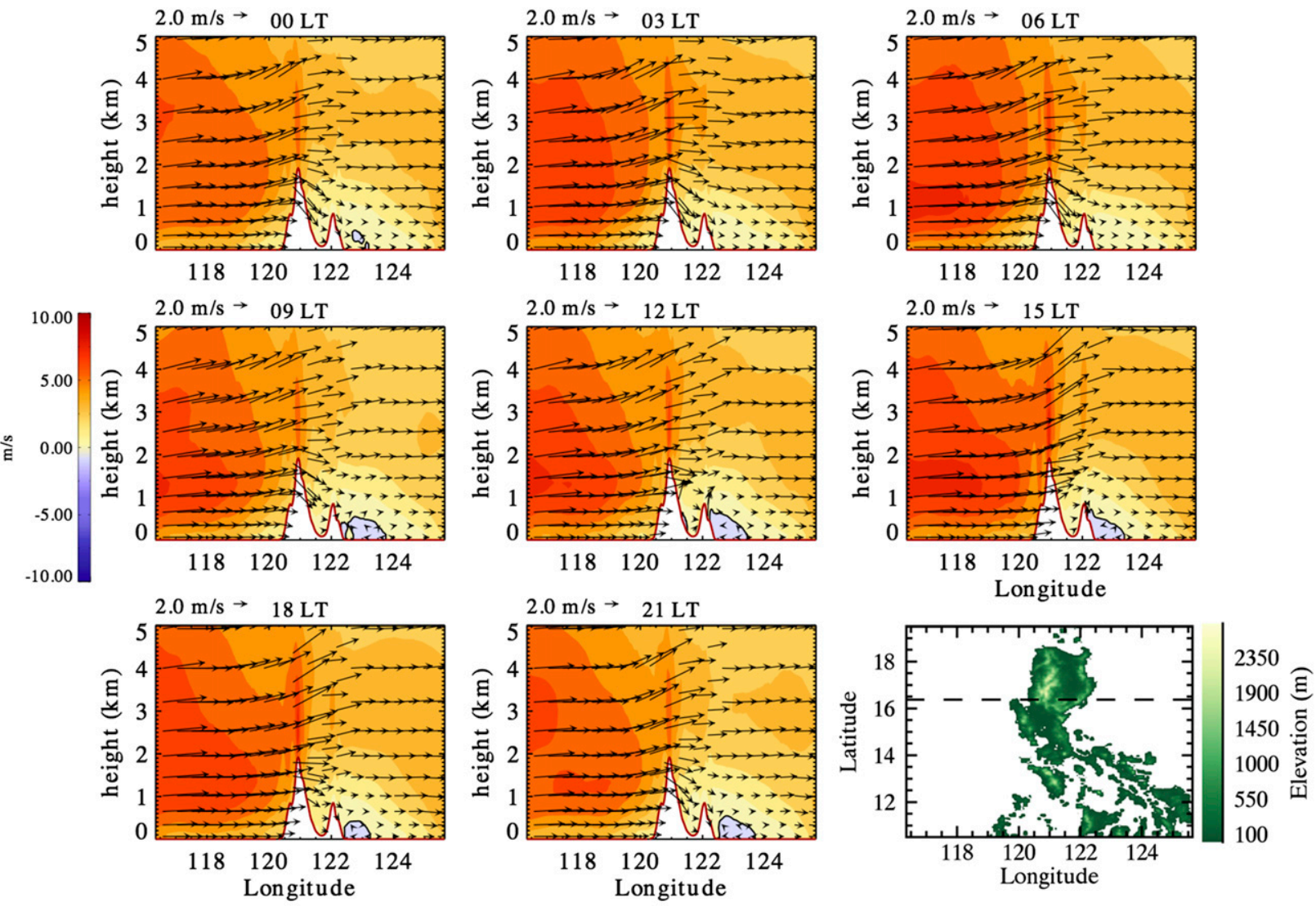

b) Potential temperature Anomalies
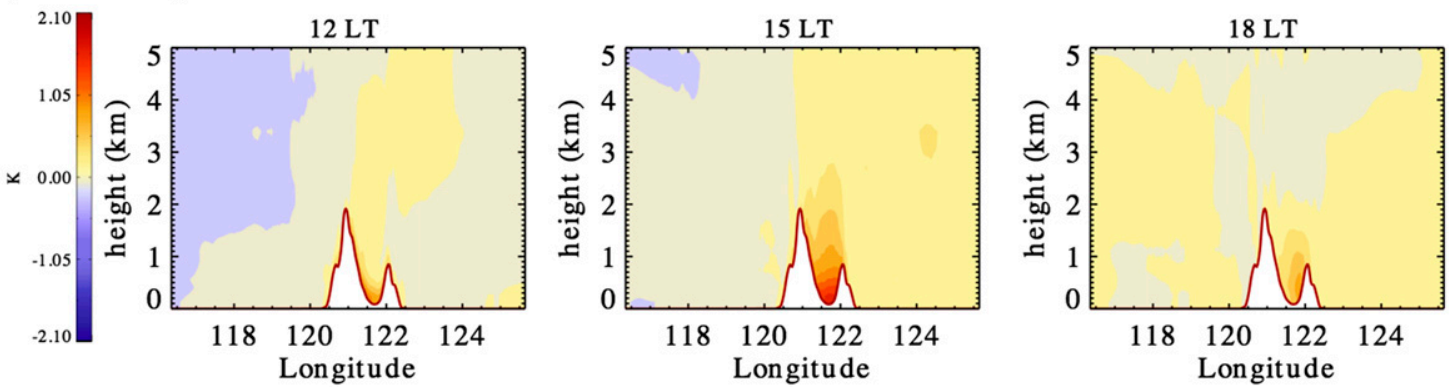

FIG. 15. As in Fig. 13, but for the true topography run and the solid red line indicates the average topography over northern Luzon for the doubled topography run.

with model-derived reflectivity at $2.4 \mathrm{~km}$ after Yuter and Houze (1997), who followed the Steiner et al. (1995) algorithm, which uses radar reflectivity intensity and peakedness to distinguish the two precipitation types. For all three runs and both large-scale conditions, except the flat run during active conditions, the convective and stratiform precipitation generally have the same DC phase (Fig. 16). For our choice of convective-stratiform separation, changes in the amount of stratiform precipitation from suppressed to active conditions do not cause the delay in the mean DCP from suppressed to active conditions in the elevated topography runs. Using another convective-stratiform algorithm (e.g., Sui et al. 2007; Penide et al. 2013; Yang et al. 2013) could potentially alter the DC composite of convective and stratiform precipitation. Penide et al. (2013) found a similar classification of stratiform rain between the Steiner et al. (1995) algorithm and a separation algorithm based on the drop size distribution (DSD) of rain, which indicates that our conclusions based on Fig. 16 are perhaps robust to their DSD method. Differences between our model findings and Sakaeda et al. (2017) may result from our 

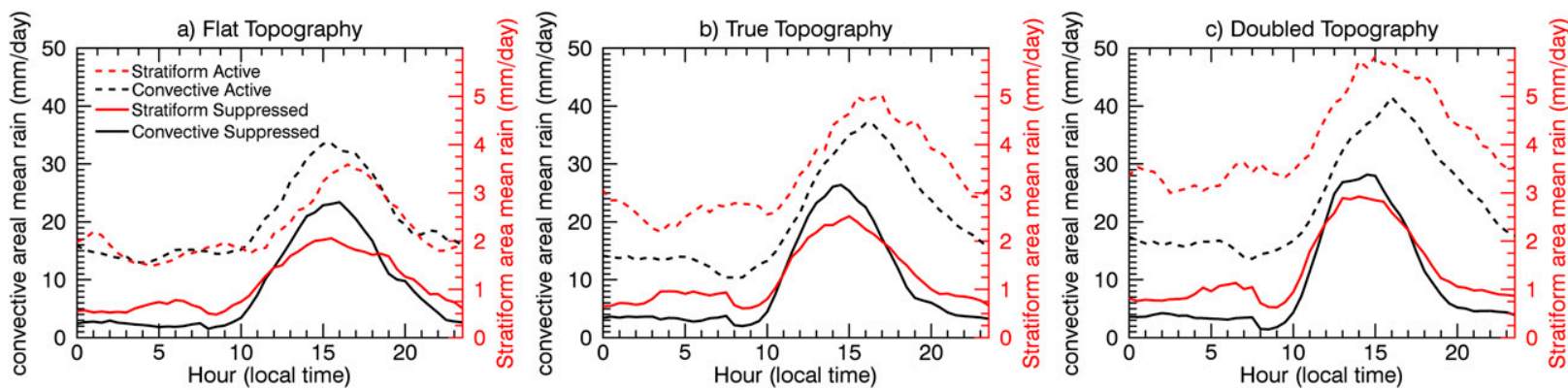

FIG. 16. Diurnal cycle composites of convective (black) and stratiform (red) areal-mean surface precipitation for the (a) flat, (b) true, and (c) doubled topography runs during suppressed (solid lines) and active (dashed lines) BSISO conditions.

focus on precipitation over Luzon versus their analysis of TRMM rainfall over all land between $15^{\circ} \mathrm{S}$ and $15^{\circ} \mathrm{N}$. Similarly, their findings related to the MJO and DC over Addu Atoll, Maldives, using rainfall from the S-PolKa radar during the Dynamics of the MJO (DYNAMO) field campaign (Sakaeda et al. 2018) may not be valid for other islands within the tropics, especially since several papers have shown that the interaction of the MJO and DC varies between MC islands (i.e., discussion in introduction).

Evaluation of the Froude number further clarifies precipitation location differences among the runs (Figs. 12c,d). In the true topography run, parcels between 1400 and $1730 \mathrm{LT}$ are able to transcend the mountains $(\mathrm{Fr} \geq 1)$ with the exception of parcels starting at $0.26 \mathrm{~km}$ from 1400 to $1530 \mathrm{LT}$ and from 1700 to $1730 \mathrm{LT}$. At other times, parcels with a starting height above $0.6 \mathrm{~km}$ are not blocked $(\mathrm{Fr} \geq 1)$ by the mountains (Fig. 12c). However, in the doubled topography run, for all times shown, only those parcels with a starting height above $1.5 \mathrm{~km}$ are able to pass over the mountains (Fig. 12d). The blockage of most parcels from passing over the mountains in the doubled topography run enables the increased confinement of precipitation to the SCS and western half of Luzon as topography increases (Fig. 6b and Figs. S4-S6).

\section{Summary and conclusions}

Three CRM simulations were run with varying topography - flat, true, and doubled topographic heightover Luzon, Philippines, during the July-August 2016 BSISO event to evaluate how changes in topography affect the DCP over Luzon and its surrounding seas during different large-scale BSISO conditions. The main conclusion is that topography helps to dictate the timing, intensity, and location of diurnal precipitation over Luzon and its surrounding seas. Elevated heterogeneous topography helps induce a later, broader, and slightly larger-amplitude afternoon mean DCP peak over land during active versus suppressed BSISO conditions. The presence of topography helps focus precipitation over the mountains during suppressed conditions and over the western half of Luzon and the SCS during active conditions. In the absence of topography (i.e., the flat run), the mean DCP peak has roughly the same timing and width for each large-scale condition and precipitation is widespread over the interior of Luzon during the day in suppressed conditions and focused on the eastern half of Luzon and the Philippine Sea during active conditions.

Mean DCP peak differences are understood by changes in mechanical and thermodynamic forcing among the three runs for each large-scale condition and are depicted in the schematics in Figs. 17 and 18. We acknowledge that the timing in the schematics does not exactly align with the timing in the mean DCP plots (Fig. 5) because we are showing 3-hourly increments in the schematic and 30-min increments in the mean DCP plot. The schematics are 3 hourly because the potential temperature anomaly and circulation plots are 3 hourly. We have based the 3-hourly schematic cartoon clouds on 3-hourly total condensate plots (not shown) to ensure fidelity in the representation of the schematic. Therefore, the schematics accurately capture the effects of topography on the overall precipitation and circulation differences between the suppressed and active conditions.

During suppressed conditions, as topography increases, the sea breeze on the west coast of Luzon deepens and has stronger onshore flow earlier in the day leading to enhanced mechanically driven upslope flow along the western slope of the western mountains (Fig. 17). Along with these sea-breeze changes, the eastern slope of the western mountains in northern Luzon has stronger valley-to-mountain upslope flow earlier in the day as topography increases due to enhanced direct thermal forcing from increasingly positive potential temperature anomalies along the elevated terrain (Fig. 17). The combination of these mechanical and thermodynamic flow differences as topography 
a) Elevated Topography
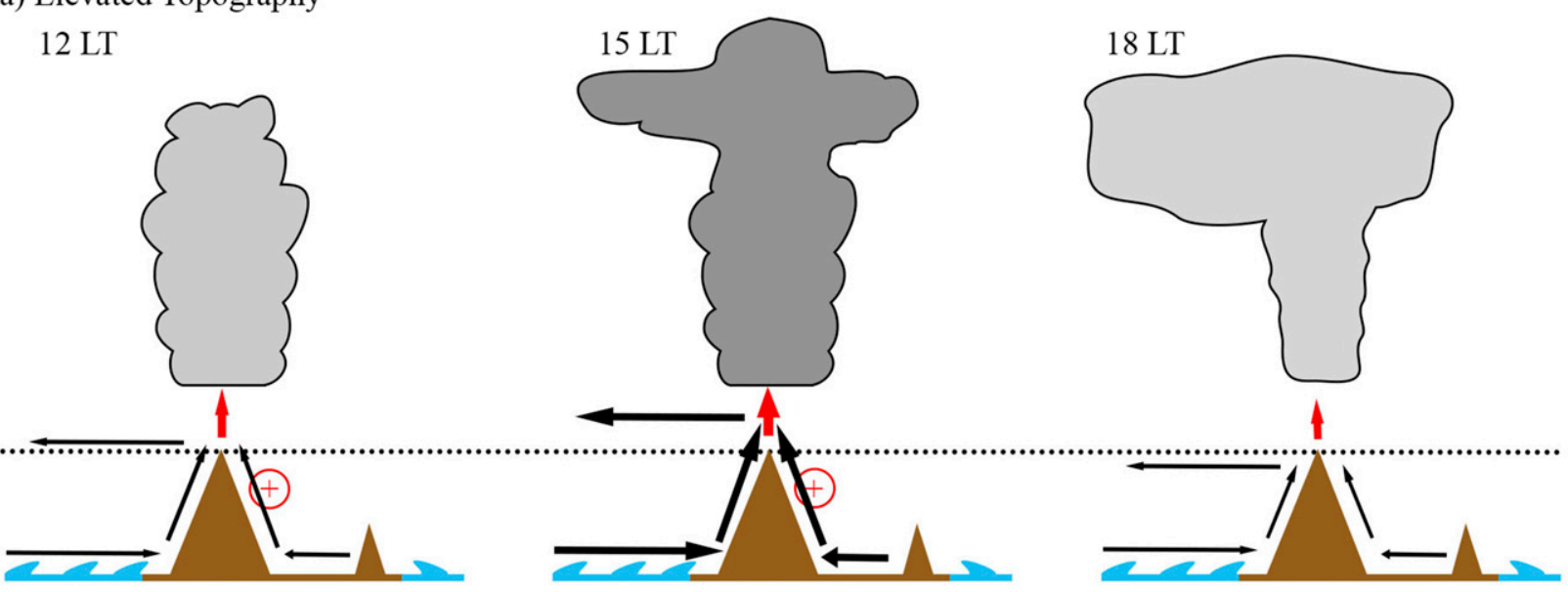

b) Flat Topography

$12 \mathrm{LT}$

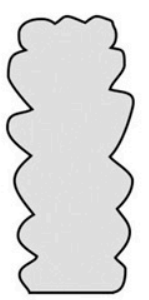

$15 \mathrm{LT}$

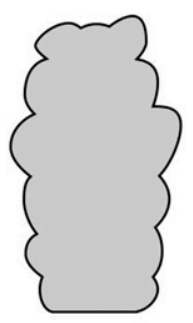

$18 \mathrm{LT}$

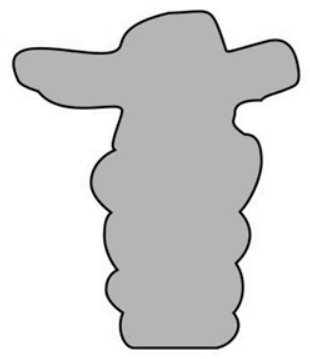

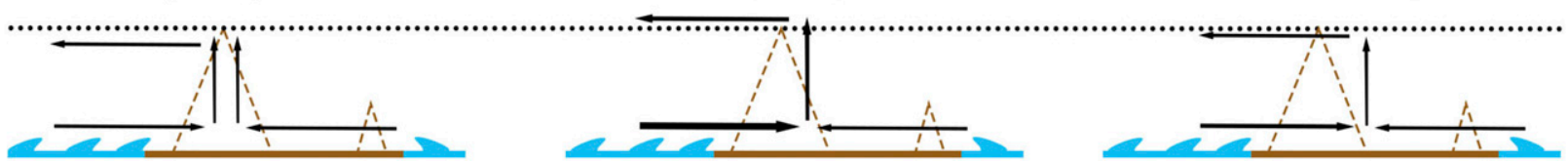

FIG. 17. Schematic of the diurnal cycle of precipitation over Luzon, Philippines, during BSISO suppressed conditions at (left) 1200 , (center) 1500, and (right) 1800 LT in the (a) elevated (i.e., true and doubled) topography runs and (b) flat topography run. The arrows represent the sea-breeze and valley-to-mountain-breeze circulations. The width of the arrows indicates the relative strength of the flow. The vertical arrows in (a) are red to emphasize the combined effect of the sea-breeze and valley-to-mountain breeze converging over the mountain. The red plus signs at 1200 and 1500 LT in (a) indicate the anomalously warm elevated temperatures at those times relative to the flat topography run and also to the daily mean at 1200 LT. The dashed mountains in (b) represent the mountain locations and are included to indicate the location of the precipitation and circulations relative to the mountains in the elevated topography runs. The gray shading of the clouds indicates the relative strength of the precipitation with darker gray indicating stronger precipitation. The horizontal dotted line is included as a reference line for the depth of the sea-breeze and valley-to-mountain breeze.

increases leads to stronger convergence earlier in the day over the western mountains. This stronger convergence earlier in the day initiates precipitation earlier in the true and doubled topography runs relative to the flat run and helps to explain the earlier stronger mean DCP peak in the elevated topography runs. During active conditions, the mechanical forcing is still present in the elevated topography runs from the southwesterlies impinging on Luzon (Fig. 18a). However, the upslope valley-to-mountain breeze is only barely present in the doubled topography run at 1200 LT. With a much weaker or completely absent valley-to-mountain breeze, convergence over the mountains in the elevated topography runs is missing (Fig. 18a). Therefore, convection in the elevated topography runs takes longer to mature relative to suppressed conditions that have stronger convergence at midday. In the flat run, the absence of mechanical forcing means the timing of the mean DCP peak is dependent upon the maximum convergence of the sea-breeze and onshore easterly flow during suppressed conditions (Fig. 17b) and maximum daytime heating during active conditions (Fig. 18b) both of which occur during the 1500 LT 3-hourly bin resulting in a similarly timed DCP peak regardless of large-scale condition.

Delays in all three runs in the maximum values of CAPE and minimum values of CIN from suppressed to active conditions further explain the delay of the mean 
a) Doubled Topography

$12 \mathrm{LT}$

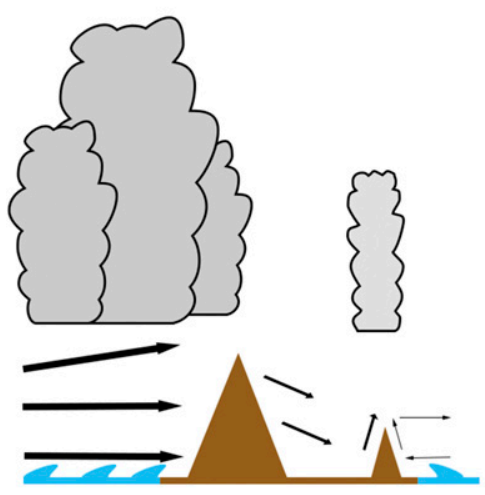

b) Flat Topography

$12 \mathrm{LT}$

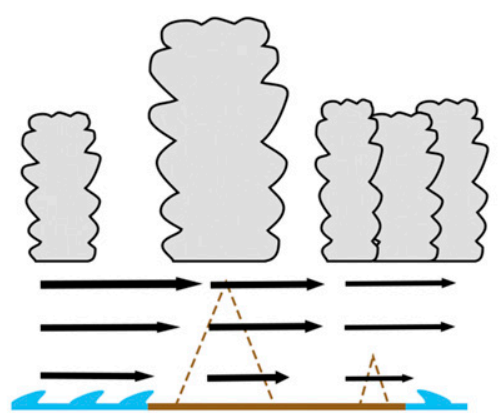

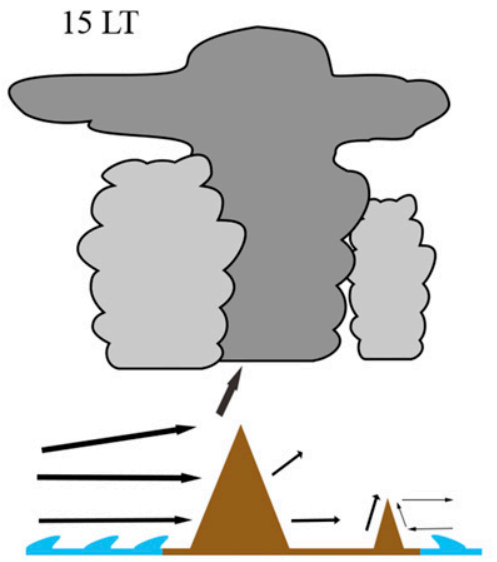

$15 \mathrm{LT}$

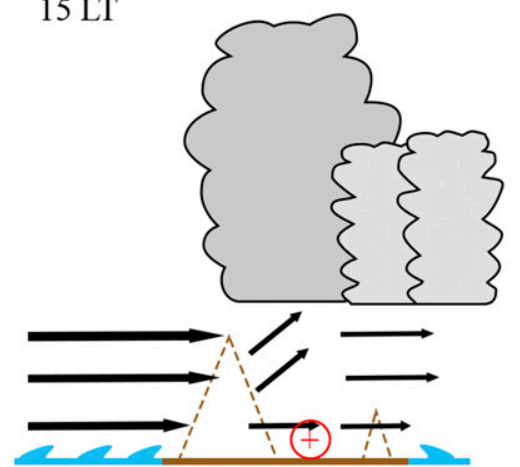

$18 \mathrm{LT}$

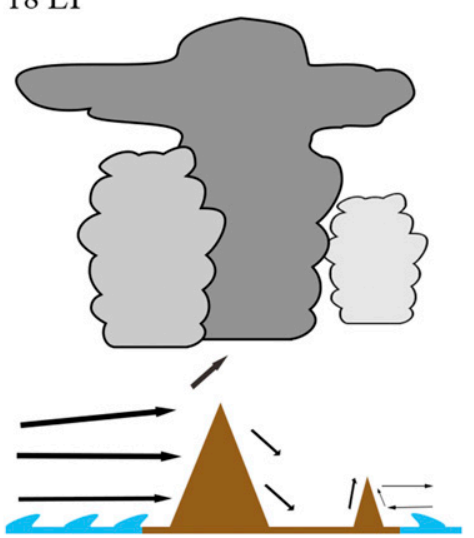

$18 \mathrm{LT}$

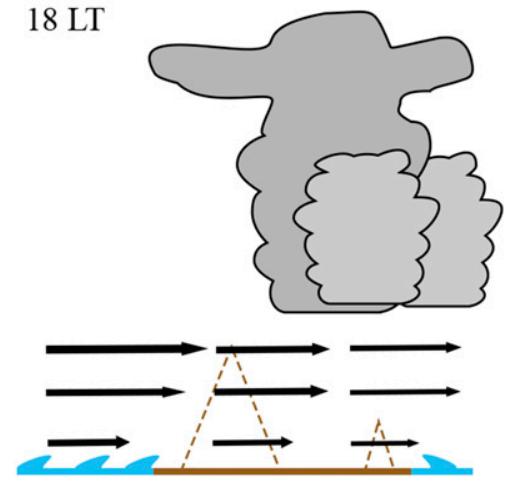

FIG. 18. Schematic of the diurnal cycle of precipitation over Luzon, Philippines, during BSISO active conditions at (left) 1200, (center) 1500, and (right) $1800 \mathrm{LT}$ in the (a) doubled topography run and (b) flat topography run. The arrows represent the zonal wind flow. The width of the arrows indicates the relative strength of the flow. The red plus sign at 1500 LT in (b) indicates the peak in the anomalously warm temperatures in the flat topography run. The dashed mountains in (b) represent the mountain locations and are included to indicate the location of the precipitation relative to the mountains in the doubled topography run. The gray shading of the clouds indicates the relative strength of the precipitation with darker gray indicating stronger precipitation.

DCP peak from suppressed to active conditions when elevated topography is present, but are inconsistent with a similarly timed mean DCP peak in the flat run for both large-scale conditions. The geographical distribution of reduced daytime CIN also clarifies location differences in precipitation among the runs. Changes in the distribution of convective versus stratiform rain did not help to explain the changes in the timing or intensity of the mean DCP as topography changed or between largescale BSISO conditions.

Froude number analysis for onshore flow along the west coast revealed that during both large-scale BSISO conditions as topography is increased, the flow became increasingly more blocked with fewer parcels being able to traverse the western mountains. This helps to explain the focus of precipitation over the top of the mountains during suppressed conditions and not in the interior of Luzon in the true and doubled topography runs, as well as the east versus west side of the domain dichotomy in precipitation during active conditions as a function of topography.

The results from this paper highlight the importance of topography to the DCP and suggest that topography cannot be ignored when modeling tropical precipitation due to its impact on the timing, intensity, and location of precipitation. Gust fronts may also be important to convective propagation during the diurnal cycle and their role may differ between the various topographic height simulations. However, it is beyond the scope of this work to objectively identify and track all of the gust fronts and their associated convective elements to pinpoint their importance. Future work will examine the role of air-sea interactions on the DCP over Luzon and its surrounding seas and evaluate whether air-sea interactions produce a similar significant impact to that of topography on the DCP. 
Acknowledgments. Discussions with Dr. Stacey Kawecki and Profs. Kristen Rasmussen and Naoko Sakaeda helped form this work and are greatly appreciated. We are grateful to Aaron Funk for providing the convective versus stratiform separation code. Comments from three anonymous reviewers improved this work. NOAA_OI_SST_V2 data provided by the NOAA/OAR/ESRL PSD, Boulder, Colorado, from their website (https://www.esrl.noaa.gov/psd/). The IMERG and TRMM 3B42 data were provided by the NASA Goddard Space Flight Center's PPS, which develop and compute the IMERG and TRMM 3B42 data as a contribution to GPM and TRMM, respectively, and are archived at the NASA GES DISC. Emily M. Riley Dellaripa and Eric D. Maloney were supported by funding and computer resources under Office of Naval Research (ONR) Grant N00014-16-1-3087, and also by NASA CYGNSS Grant NNX17AH77G and NOAA CVP Project NA18OAR4310299. Benjamin A. Toms was funded by ONR Grant N00014-16-1-3093 and the Department of Energy Computational Science Graduate Fellowship via Grant DE-FG02-97ER25308. Stephen M. Saleeby was funded by NASA Grant 80NSSC18K0149. Susan C. van den Heever was supported by ONR Grant N00014-16-1-3093.

\section{REFERENCES}

Barthlott, C., and D. J. Kirshbaum, 2013: Sensitivity of deep convection to terrain forcing over Mediterranean islands. Quart. J. Roy. Meteor. Soc., 139, 1762-1779, https://doi.org/10.1002/ qj.2089.

Behrendt, A., and Coauthors, 2011: Observation of convection initiation processes with a suite of state-of-the-art research instruments during COPS IOP 8b. Quart. J. Roy. Meteor. Soc., 137, 81-100, https://doi.org/10.1002/qj.758.

Birch, C. E., S. Webster, S. C. Peatman, D. J. Parker, A. J. Matthews, Y. Li, and M. E. E. Hassim, 2016: Scale interactions between the $\mathrm{MJO}$ and the western Maritime Continent. J. Climate, 29, 2471-2492, https://doi.org/10.1175/JCLI-D-15-0557.1.

Bryan, G. H., J. C. Wyngaard, and J. M. Fritsch, 2003: Resolution requirements for the simulation of deep moist convection. Mon. Wea. Rev., 131, 2394-2416, https://doi.org/10.1175/15200493(2003)131<2394:RRFTSO > 2.0.CO;2.

Chen, S. S., and R. A. Houze Jr., 1997: Diurnal variation and lifecycle of deep convective systems over the tropical Pacific warm pool. Quart. J. Roy. Meteor. Soc., 123, 357-388, https:// doi.org/10.1002/qj.49712353806.

Chen, T., and K. Takahashi, 1995: Diurnal variation of outgoing longwave radiation in the vicinity of the South China Sea: Effect of intraseasonal oscillation. Mon. Wea. Rev., 123, 566-577, https://doi.org/10.1175/1520-0493(1995)123<0566: DVOOLR $>2.0 . \mathrm{CO} ; 2$.

Copernicus Climate Change Service, 2017: ERA5: Fifth generation of ECMWF atmospheric reanalyses of the global climate. Copernicus Climate Change Service Climate Data Store, accessed 21 November 2017, https://cds.climate.copernicus.eu/ cdsapp\#!/home.
Cotton, W. R., and Coauthors, 2003: RAMS 2001: Current status and future directions. Meteor. Atmos. Phys., 82, 5-29, https:// doi.org/10.1007/s00703-001-0584-9.

Davies, H. C., 1976: A lateral boundary formulation for multi-level prediction models. Quart. J. Roy. Meteor. Soc., 102, 405-418, https://doi.org/10.1002/qj.49710243210.

Dee, D. P., and Coauthors, 2011: The ERA-Interim reanalysis: Configuration and performance of the data assimilation system. Quart. J. Roy. Meteor. Soc., 137, 553-597, https://doi.org/10.1002/qj.828.

Del Genio, A. D., and J. Wu, 2010: The role of entrainment in the diurnal cycle of continental convection. J. Climate, 23, 27222738, https://doi.org/10.1175/2009JCLI3340.1.

Demko, J. C., and B. Geerts, 2010: A numerical study of the evolving convective boundary layer and orographic circulation around the Santa Catalina Mountains in Arizona. Part II: Interaction with deep convection. Mon. Wea. Rev., 138, 36033622, https://doi.org/10.1175/2010MWR3318.1.

DeMott, P. J., and Coauthors, 2010: Predicting global atmospheric ice nuclei distributions and their impacts on climate. Proc. Natl. Acad. Sci. USA, 107, 11217-11222, https://doi.org/10.1073/ pnas.0910818107.

Emanuel, K. A., and M. Živković-Rothman, 1999: Development and evaluation of a convection scheme for use in climate models. J. Atmos. Sci., 56, 1766-1782, https://doi.org/10.1175/ 1520-0469(1999)056<1766:DAEOAC >2.0.CO;2.

Hagos, S. M., C. Zhang, Z. Feng, C. D. Burleyson, C. De Mott, B. Kerns, J. J. Benedict, and M. N. Martini, 2016: The impact of the diurnal cycle on the propagation of MJO convection across the Maritime Continent. J. Adv. Model. Earth Syst., 8, 1552-1564, https://doi.org/10.1002/2016MS000725.

Harrington, J. Y., 1997: The effects of radiative and microphysical processes on simulated warm and transition season Arctic stratus. Ph.D. dissertation, Dept. of Atmospheric Science, Colorado State University, 289 pp.

Hassim, M. E. E., T. P. Lane, and W. W. Grabowski, 2016: The diurnal cycle of rainfall over New Guinea in convectionpermitting WRF simulations. Atmos. Chem. Phys., 16, 161-175, https://doi.org/10.5194/acp-16-161-2016.

Ho, C., M. Park, Y. Choi, and Y. N. Takayabu, 2008: Relationship between intraseasonal oscillation and diurnal variation of summer rainfall over the South China Sea. Geophys. Res. Lett., 35, L03701, https://doi.org/10.1029/2007GL031962.

Houze, R. A., Jr., 2012: Orographic effects on precipitating clouds. Rev. Geophys., 50, RG1001, https://doi.org/10.1029/2011RG000365.

Hsu, H., and M. Lee, 2005: Topographic effects on the eastward propagation and initiation of the Madden-Julian oscillation. J. Climate, 18, 795-809, https://doi.org/10.1175/JCLI-3292.1.

Huffman, G. J., and D. T. Bolvin, 2018: TRMM and other data precipitation data set documentation. NASA GSFC Rep., 46 pp., https://pmm.nasa.gov/sites/default/files/document_files/ 3B42_3B43_doc_V7_180426.pdf.

- and Coauthors, 2007: The TRMM Multisatellite Precipitation Analysis (TMPA): Quasi-global, multiyear, combined-sensor precipitation estimates at fine scales. J. Hydrometeor., 8, 38-55, https://doi.org/10.1175/JHM560.1.

—, D. T. Bolvin, and E. J. Nelkin, 2018: Integrated MultiSatellite Retrievals for GPM (IMERG) technical documentation. NASA GSFC Rep., 60 pp., https://pmm.nasa.gov/sites/ default/files/document_files/IMERG_doc_180207.pdf.

Ichikawa, H., and T. Yasunari, 2006: Time-space characteristics of diurnal rainfall over Borneo and surrounding oceans as observed by TRMM-PR. J. Climate, 19, 1238-1260, https://doi.org/10.1175/ JCLI3714.1. 
Igel, M. R., S. R. Herbener, and S. M. Saleeby, 2017: The tropical precipitation pickup threshold and clouds in a radiative convective equilibrium model: 1. Column moisture. J. Geophys. Res. Atmos., 122, 6453-6468, https://doi.org/10.1002/2016JD025907.

Inness, P. M., and J. M. Slingo, 2006: The interaction of the Madden-Julian oscillation with the Maritime Continent in a GCM. Quart. J. Roy. Meteor. Soc., 132, 1645-1667, https:// doi.org/10.1256/qj.05.102.

Jiang, X., and Coauthors, 2015: Vertical structure and physical processes of the Madden-Julian oscillation: Exploring key model physics in climate simulations. J. Geophys. Res. Atmos., 120, 4718-4748, https://doi.org/10.1002/2014JD022375.

Kikuchi, K., B. Wang, and Y. Kajikawa, 2012: Bimodal representation of the tropical intraseasonal oscillation. Climate Dyn., 38, 1989-2000, https://doi.org/10.1007/s00382-011-1159-1.

Kim, K., J. Park, J. Baik, and M. Choi, 2017: Evaluation of topographical and seasonal feature using GPM IMERG and TRMM 3B42 over far-East Asia. Atmos. Res., 187, 95-105, https://doi.org/10.1016/j.atmosres.2016.12.007.

Kirshbaum, J. D., B. Adler, N. Kalthoff, C. Barthlott, and S. Serafin, 2018: Moist orographic convection: Physical mechanisms and links to surface-exchange processes. Atmosphere, 9, 80, https:// doi.org/10.3390/atmos9030080.

Knutson, T. R., and K. M. Weickmann, 1987: 30-60 day atmospheric oscillations: Composite life cycles of convection and circulation anomalies. Mon. Wea. Rev., 115, 1407-1436, https:// doi.org/10.1175/1520-0493(1987)115<1407:DAOCLC > 2.0.CO;2.

Ladwig, W., 2017: wrf-python, version 1.1.3 [wrf.cape_2D]. GitHub, https://doi.org/10.5065/D6W094P1.

Lee, J., B. Wang, M. C. Wheeler, X. Fu, D. E. Waliser, and I. Kang, 2013: Real-time multivariate indices for the boreal summer intraseasonal oscillation over the Asian summer monsoon region. Climate Dyn., 40, 493-509, https://doi.org/10.1007/ s00382-012-1544-4.

Liu, C. T., and E. J. Zipser, 2008: Diurnal cycles of precipitation, clouds, and lightning in the tropics from 9 years of TRMM observations. Geophys. Res. Lett., 35, L04819, https://doi.org/ 10.1029/2007GL032437

Liu, P., and Coauthors, 2009: An MJO simulated by the NICAM at 14- and 7-km resolutions. Mon. Wea. Rev., 137, 3254-3268, https://doi.org/10.1175/2009MWR2965.1.

Liu, Z., 2016: Comparison of Integrated Multisatellite Retrievals for GPM (IMERG) and TRMM Multisatellite Precipitation Analysis (TMPA) monthly precipitation products: Initial results. J. Hydrometeor., 17, 777-790, https://doi.org/10.1175/ JHM-D-15-0068.1.

Madden, R. A., and P. R. Julian, 1972: Description of global-scale circulation cells in tropics with a 40-50 day period. J. Atmos. Sci., 29, 1109-1123, https://doi.org/10.1175/1520-0469(1972) 029<1109:DOGSCC > 2.0.CO;2.

Maloney, E. D., and D. L. Hartmann, 1998: Frictional moisture convergence in a composite life cycle of the Madden-Julian oscillation. J. Climate, 11, 2387-2403, https://doi.org/10.1175/ 1520-0442(1998)011<2387:FMCIAC >2.0.CO;2.

Matthews, A. J., G. Pickup, S. C. Peatman, P. Clews, and J. Martin, 2013: The effect of the Madden-Julian oscillation on station rainfall and river level in the Fly River system, Papua New Guinea. J. Geophys. Res., 118, $10926-10935$, https://doi.org/ 10.1002/jgrd.50865.

Meyers, M. P., R. L. Walko, J. Y. Harrington, and W. R. Cotton, 1997: New RAMS cloud microphysics parameterization. Part II: The two-moment scheme. Atmos. Res., 45, 3-39, https:// doi.org/10.1016/S0169-8095(97)00018-5.
Neale, R., and J. Slingo, 2003: The Maritime Continent and its role in the global climate: A GCM study. J. Climate, 16, 834-848, https:// doi.org/10.1175/1520-0442(2003)016<0834:TMCAIR>2.0.CO;2.

Neena, J. M., D. Waliser, and X. Jiang, 2017: Model performance metrics and process diagnostics for boreal summer intraseasonal variability. Climate Dyn., 48, 1661-1683, https://doi.org/ 10.1007/s00382-016-3166-8.

Nesbitt, S. W., and E. J. Zipser, 2003: The diurnal cycle of rainfall and convective intensity according to three years of TRMM measurements. J. Climate, 16, 1456-1475, https://doi.org/10.1175/ 1520-0442-16.10.1456.

Oh, J., B. Kim, K. Kim, H. Song, and G. Lim, 2013: The impact of the diurnal cycle on the MJO over the Maritime Continent: A modeling study assimilating TRMM rain rate into global analysis. Climate Dyn., 40, 893-911, https://doi.org/10.1007/ s00382-012-1419-8.

Park, M., C. Ho, J. Kim, and R. L. Elsberry, 2011: Diurnal circulations and their multi-scale interaction leading to rainfall over the South China Sea upstream of the Philippines during intraseasonal monsoon westerly wind bursts. Climate Dyn., 37, 1483-1499, https://doi.org/10.1007/s00382-010-0922-z.

Peatman, S. C., A. J. Matthews, and D. P. Stevens, 2014: Propagation of the Madden-Julian oscillation through the Maritime Continent and scale interaction with the diurnal cycle of precipitation. Quart. J. Roy. Meteor. Soc., 140, 814-825, https:// doi.org/10.1002/qj.2161.

Penide, G., A. Protat, V. V. Kumar, and P. T. May, 2013: Comparison of two convective/stratiform precipitation classification techniques: Radar reflectivity texture versus drop size distribution-based approach. J. Atmos. Oceanic Technol., 30, 2788-2797, https://doi.org/10.1175/JTECH-D-13-00019.1.

Pielke, R. A., and Coauthors, 1992: A comprehensive meteorological modeling system-RAMS. Meteor. Atmos. Phys., 49, 69-91, https://doi.org/10.1007/BF01025401.

Qian, J., 2008: Why precipitation is mostly concentrated over islands in the Maritime Continent. J. Atmos. Sci., 65, 1428-1441, https://doi.org/10.1175/2007JAS2422.1.

Rajendran, K., A. Kitoh, R. Mizuta, S. Sajani, and T. Nakazawa, 2008: High-resolution simulation of mean convection and its intraseasonal variability over the tropics in the MRI/JMA 20-km mesh AGCM. J. Climate, 21, 3722-3739, https://doi.org/ 10.1175/2008JCLI1950.1.

Rasmussen, K. L., and R. A. Houze, 2016: Convective initiation near the Andes in subtropical South America. Mon. Wea. Rev., 144, 2351-2374, https://doi.org/10.1175/MWR-D-150058.1.

- S. L. Choi, M. D. Zuluaga, and R. A. Houze Jr., 2013: TRMM precipitation bias in extreme storms in South America. Geophys. Res. Lett., 40, 3457-3461, https://doi.org/10.1002/grl.50651.

Rauniyar, S. P., and K. J. E. Walsh, 2011: Scale interaction of the diurnal cycle of rainfall over the Maritime Continent and Australia: Influence of the MJO. J. Climate, 24, 325-348, https:// doi.org/10.1175/2010JCLI3673.1.

Reynolds, R. W., N. A. Rayner, T. M. Smith, D. C. Stokes, and W. Wang, 2002: An improved in situ and satellite SST analysis for climate. J. Climate, 15, 1609-1625, https://doi.org/10.1175/ 1520-0442(2002)015<1609:AIISAS > 2.0.CO;2.

Riley, E. M., B. E. Mapes, and S. N. Tulich, 2011: Clouds associated with the Madden-Julian oscillation: A new perspective from CloudSat. J. Atmos. Sci., 68, 3032-3051, https://doi.org/10.1175/ JAS-D-11-030.1.

Sakaeda, N., G. Kiladis, and J. Dias, 2017: The diurnal cycle of tropical cloudiness and rainfall associated with the 
Madden-Julian oscillation. J. Climate, 30, 3999-4020, https:// doi.org/10.1175/JCLI-D-16-0788.1.

— S. W. Powell, J. Dias, and G. N. Kiladis, 2018: The diurnal variability of precipitating cloud populations during DYNAMO. J. Atmos. Sci., 75, 1307-1326, https://doi.org/10.1175/ JAS-D-17-0312.1.

Saleeby, S. M., and W. R. Cotton, 2004: A large-droplet mode and prognostic number concentration of cloud droplets in the Colorado State University Regional Atmospheric Modeling System (RAMS). Part I: Module descriptions and supercell test simulations. J. Appl. Meteor., 43, 182-195, https://doi.org/ 10.1175/1520-0450(2004)043<0182:ALMAPN>2.0.CO;2.

— , and S. C. van den Heever, 2013: Developments in the CSU-RAMS aerosol model: Emissions, nucleation, regeneration, deposition, and radiation. J. Appl. Meteor. Climatol., 52, 26012622, https://doi.org/10.1175/JAMC-D-12-0312.1.

Scheel, M. L. M., M. Rohrer, C. Huggel, D. Santos Villar, E. Silvestre, and G. J. Huffman, 2011: Evaluation of TRMM Multi-Satellite Precipitation Analysis (TMPA) performance in the central Andes region and its dependency on spatial and temporal resolution. Hydrol. Earth Syst. Sci., 15, 2649-2663, https://doi.org/10.5194/hess-15-2649-2011.

Sobel, A. H., E. D. Maloney, G. Bellon, and D. M. Frierson, 2010: Surface fluxes and tropical intraseasonal variability: A reassessment. J. Adv. Model. Earth Syst., 2 (1), https://doi.org/10.3894/ JAMES.2010.2.2.

Steiner, M., R. A. Houze, and S. E. Yuter, 1995: Climatological characterization of three-dimensional storm structure from operational radar and rain gauge data. J. Appl. Meteor., 34, 1978-2007, https://doi.org/10.1175/1520-0450(1995)034<1978: CCOTDS $>2.0 . \mathrm{CO} ; 2$.

Stirling, A. J., and R. A. Stratton, 2012: Entrainment processes in the diurnal cycle of deep convection over land. Quart. J. Roy. Meteor. Soc., 138, 1135-1149, https://doi.org/10.1002/qj.1868.

Sui, C., and K. Lau, 1992: Multiscale phenomena in the tropical atmosphere over the western Pacific. Mon. Wea. Rev., 120, 407-430, https://doi.org/10.1175/1520-0493(1992)120<0407: MPITTA $>2.0 . C O ; 2$.

,-- , Y. N. Takayabu, and D. A. Short, 1997a: Diurnal variations in tropical oceanic cumulus convection during TOGA COARE. J. Atmos. Sci., 54, 639-655, https://doi.org/10.1175/ 1520-0469(1997)054<0639:DVITOC >2.0.CO;2.

—, X. Li, K. Lau, and D. Adamec, 1997b: Multiscale air-sea interactions during TOGA COARE. Mon. Wea. Rev., 125, 448-462, https://doi.org/10.1175/1520-0493(1997)125<0448: MASIDT $>2.0 . \mathrm{CO} ; 2$.

— C. Tsay, and X. Li, 2007: Convective-stratiform rainfall separation by cloud content. J. Geophys. Res., 112, D14213, https://doi.org/10.1029/2006JD008082.

Tan, H., P. Ray, B. S. Barrett, M. Tewari, and M. W. Moncrieff, 2018: Role of topography on the MJO in the maritime continent: A numerical case study. Climate Dyn., https://doi.org/ 10.1007/s00382-018-4275-3, in press.

Tian, B., D. E. Waliser, and E. J. Fetzer, 2006: Modulation of the diurnal cycle of tropical deep convective clouds by the MJO. Geophys. Res. Lett., 33, L20704, https://doi.org/10.1029/2006GL027752.

Toms, B. A., S. C. van den Heever, E. M. Riley Dellaripa, S. M. Saleeby, and E. D. Maloney, 2019: The boreal summer Madden-Julian oscillation and moist convective morphology over the Maritime Continent. J. Atmos. Sci., https://doi.org/ 10.1175/JAS-D-19-0029.1, in press.

Tseng, W., H. Hsu, N. Keenlyside, C. June Chang, B. Tsuang, C. Tu, and L. Jiang, 2017: Effects of surface orography and land-sea contrast on the Madden-Julian oscillation in the Maritime Continent: A numerical study using ECHAM5-SIT. J. Climate, 30, 9725-9741, https://doi.org/10.1175/JCLI-D-170051.1.

Viale, M., R. A. Houze Jr., and K. L. Rasmussen, 2013: Upstream orographic enhancement of a narrow cold-frontal rainband approaching the Andes. Mon. Wea. Rev., 141, 1708-1730, https://doi.org/10.1175/MWR-D-12-00138.1.

Vincent, C. L., and T. P. Lane, 2016: Evolution of the diurnal precipitation cycle with the passage of a Madden-Julian oscillation event through the Maritime Continent. Mon. Wea. Rev., 144, 1983-2005, https://doi.org/10.1175/MWR-D-15-0326.1.

— observed and modeled intraseasonal, mesoscale, and diurnal variations over the Maritime Continent. J. Climate, 30, 38073828, https://doi.org/10.1175/JCLI-D-16-0688.1.

Walko, R. L., and C. J. Tremback, 2005: Modifications for the transition from LEAF-2 to LEAF. ATMET Tech. Note 1, 13 pp., http://www.atmet.com/html/docs/rams/RT1-leaf2-3.pdf.

—, W. R. Cotton, M. P. Meyers, and J. Y. Harrington, 1995: New RAMS cloud microphysics parameterization part I: The singlemoment scheme. Atmos. Res., 38, 29-62, https://doi.org/10.1016/ 0169-8095(94)00087-T.

_ , and Coauthors, 2000: Coupled atmosphere-biophysicshydrology models for environmental modeling. J. Appl. Meteor., 39, 931-944, https://doi.org/10.1175/1520-0450(2000) 039<0931:CABHMF $>2.0 . \mathrm{CO} ; 2$.

Wang, D., X. Wang, L. Liu, D. Wang, H. Huang, and C. Pan, 2018: Evaluation of TMPA 3B42V7, GPM IMERG and CMPA precipitation estimates in Guangdong Province, China. Int J. Climatol., 39, 738-755, https://doi.org/10.1002/joc.5839.

Wang, Y., C. N. Long, J. H. Mather, and X. Liu, 2011: Convective signals from surface measurements at ARM tropical western Pacific site: Manus. Climate Dyn., 36, 431-449, https://doi.org/ 10.1007/s00382-009-0736-z.

Wu, C., and H. Hsu, 2009: Topographic influence on the MJO in the Maritime Continent. J. Climate, 22, 5433-5448, https://doi.org/ 10.1175/2009JCLI2825.1.

Wu, Q., and Y. Wang, 2019: Comparison of oceanic multisatellite precipitation data from Tropical Rainfall Measurement Mission and Global Precipitation Measurement Mission datasets with rain gauge data from ocean buoys. J. Atmos. Oceanic Technol., 36, 903-920, https://doi.org/10.1175/JTECH-D-18-0152.1.

Yang, Y., X. Chen, and Y. Qi, 2013: Classification of convective/ stratiform echoes in radar reflectivity observations using a fuzzy logic algorithm. J. Geophys. Res. Atmos., 118, 18961905, https://doi.org/10.1002/jgrd.50214.

Yokoi, S., S. Mori, M. Katsumata, B. Geng, K. Yasunaga, F. Syamsudin, Nurhayati, and K. Yoneyama, 2017: Diurnal cycle of precipitation observed in the western coastal area of Sumatra Island: Offshore preconditioning by gravity waves. Mon. Wea. Rev., 145, 3745-3761, https://doi.org/10.1175/MWR-D-16-0468.1.

Yuter, S. E., and R. A. Houze, 1997: Measurements of raindrop size distributions over the Pacific warm pool and implications for Z-R relations. J. Appl. Meteor., 36, 847-867, https://doi.org/ 10.1175/1520-0450(1997)036<0847:MORSDO > 2.0.CO;2.

Zhang, C. D., 2005: Madden-Julian oscillation. Rev. Geophys., 43, RG2003, https://doi.org/10.1029/2004RG000158.

Zhu, L., Z. Meng, F. Zhang, and P. M. Markowski, 2017: The influence of sea- and land-breeze circulations on the diurnal variability in precipitation over a tropical island. Atmos. Chem. Phys., 17, 13 213-13 232, https://doi.org/10.5194/acp-1713213-2017. 